Chimia 45 (199I) 55-56

(C) Schweiz. Chemiker-Verband; ISSN 0009-4293 mate, L-aspartate, and S-containing amino acids such as homocysteate or L-cysteine sulfinic acid [8].

\section{Excitatory Amino-Acid Antagonists and Their Possible Clinical Application}

\author{
Peter Frey*
}

Abstract. A brief review of the pharmacology of some excitatory amino-acid receptor antagonists, active at the $N$-methyl-D-aspartate receptor subtype, and prospects of their possible therapeutic indication are given.

\section{Introduction}

The Sandoz Research Institute in Berne (formerly the WanderResearch Institute) has a longstanding tradition of central nervous system (CNS) research and the development of centrally active drugs. For several years now, part of our activities have been focussed in the field of excitatory amino acids. The following article is a short review of this highly competitive field.

Almost fourty years ago, the convulsant action of L-glutamate was reported [1], and a few years later, it was shown through intracellular recording that $\mathrm{L}-$ glutamic acid is able to depolarize and excite single neurons of the central nervous system [2]. Immediately after this initial discovery, structure-activity studies were undertaken, and it became clear that such effects were receptormediated. A search for agonists and antagonists began. It was found that, besides $\mathrm{L}^{-}$ glutamate, other dicarboxylic amino acids like $L$-aspartate or $S$-containing amino acids like homocysteic acid were able to excite neurons. Two other excitants, namely kainic acid, isolated from marine algae, and quisqualic acid, isolated from a plant, were crucial in the finding that there exist at least three different subtypes of excitatory amino-acid (EAA) receptors in the mammalian central nervous system [3] [4]. These subtypes were named after their specific agonists $N$ methyl-D-aspartate (NMDA), kainate (KA), and quisqualate (QUIS). With $\alpha$-amino-3hydroxy-5-methyl-4-isoxazolepropionic acid (AMPA) [5], a more specific agonist for the QUIS receptor has been synthesized, and in addition, it has been discovered that quisqualate activates also a fourth EAA-receptor subtype which is not linked to an ion channel but, instead, stimulates phosphoionositol metabolism [6]. Therefore, although the NMDA, KA, QUIS nomenclature is still widely used, a reclassification of the receptor names is currently under consideration. An extensive series of review articles concerning the field of excitatory amino acids has recently been published [7]. Despite the relatively wide knowledge of the physiology and the function of excitatory amino-acid receptors in the central nervous system, the naturally occurring neurotransmitters in the brain are not known. The most likely candidate for this role, however, are L-gluta-

Agonists at excitatory amino-acid receptors

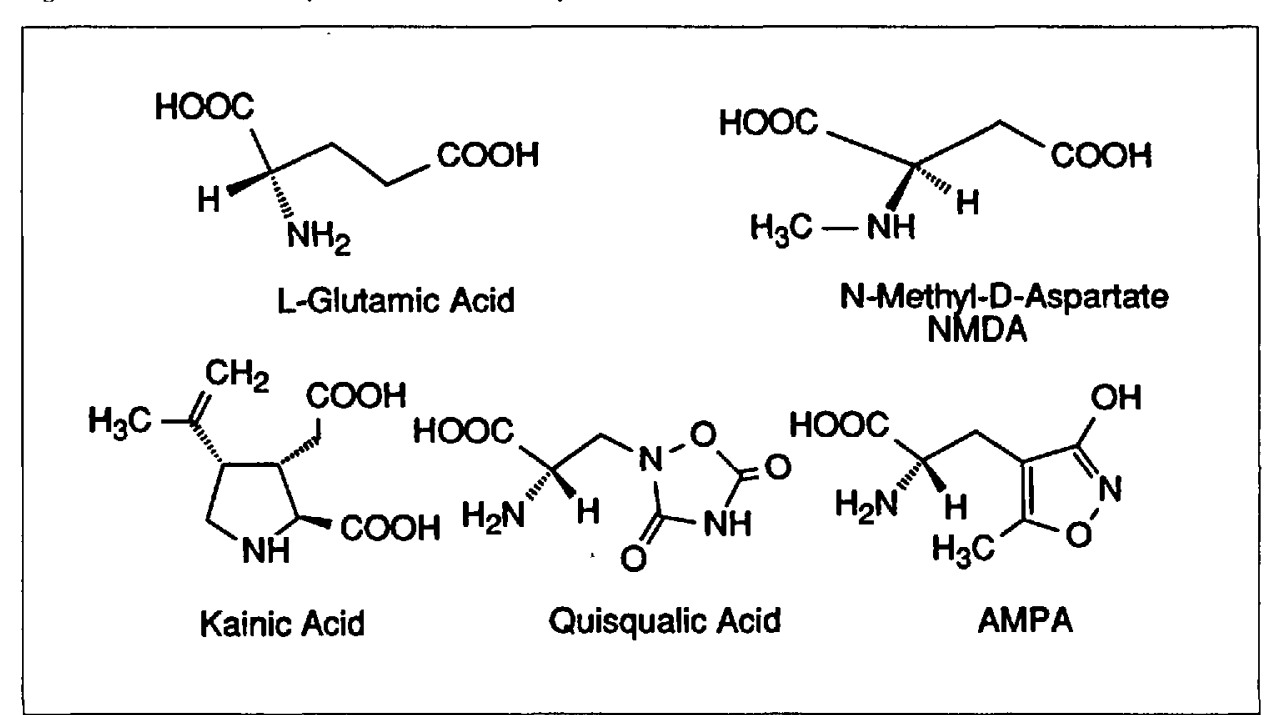

Scheme. Competitive antagonists of the $\mathrm{N}$-methyl-D-aspartate receptor subtype

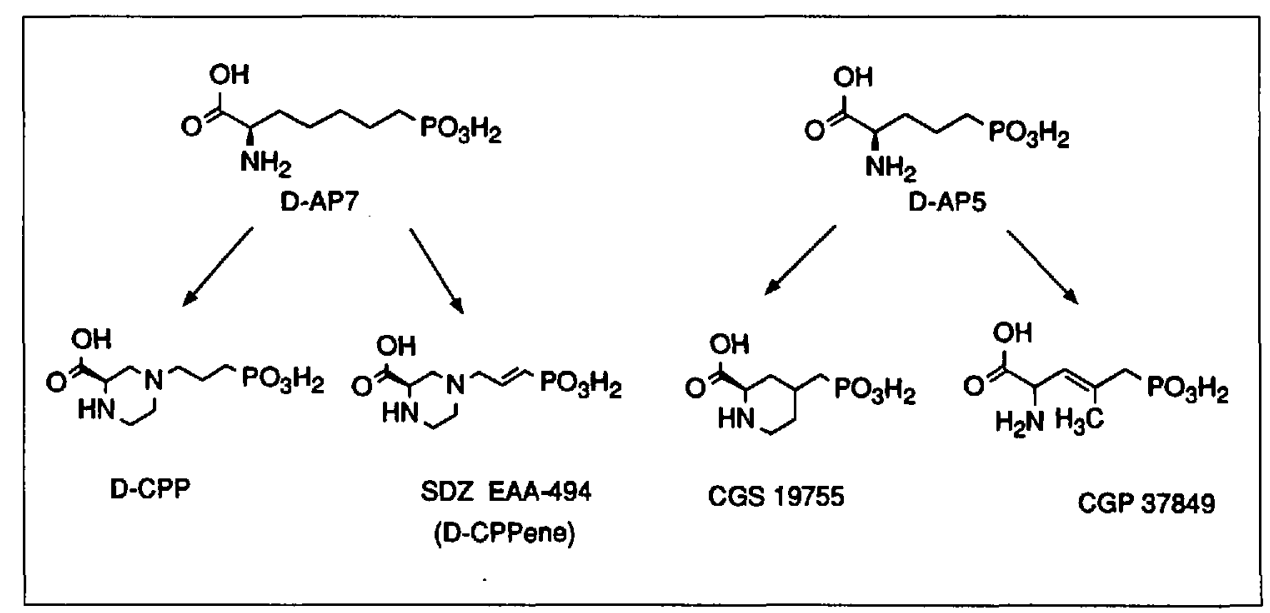
restricting the conformational flexibility of

\section{NMDA Antagonists}

Criteria for the characterization of the NMDA receptor were $a$ ) that it can be blocked selectively by $\mathrm{Mg}^{2+}[9]$ and $b$ ) by its sensitivity to selective competitive antagonists such as D-2-amino-5-phosphonopentanoic acid (D-AP-5) and D-2-amino-7-phosphonoheptanoic acid (D-AP-7) [10] (see Scheme). $\mathrm{Mg}^{2+}$ blocks the NMDA-gated ion channel on neurones. The competitive antagonists were obtained by varying the sidechain length of aspartic acid and by replacing the carboxylic acid on this chain with a phosphonate group. These antagonists are active at micromolar concentrations. By AP-7, even stronger antagonists were obtained:4-(3-phosphonopropyl)piperazine-2carboxylic acid (D-CPP) [1 11 , and $(R)-4-I(E)$ 3-phosphonoprop-2-enyl]piperazine-2-carboxylic acid (D-CPPene, SDZ EAA-494) [12]. In a similar fashion, AP-5 was modified resulting in cis-4-(phosphonomethyl)-2piperidine carboxylic acid (CGS 19755) [13] 
Non-competitive antagonists of the N-methyl-D-aspartate receptor subtype
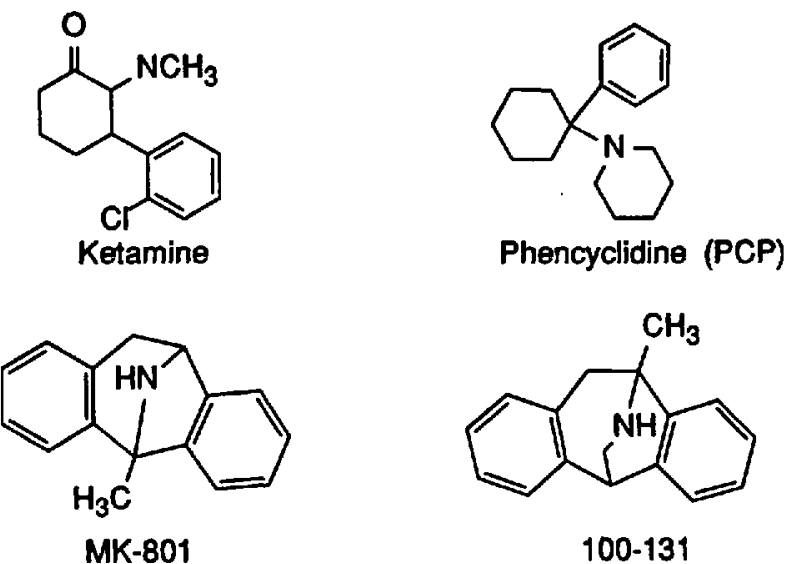

100-131 and $(R S, E)$-2-amino-4-methyl-5-phosphono-3-pentenoic acid (CGP 37849) [14]. SDZ EAA-494 (D-CPPene) and CGP 37849 are the most potent competitive NMDA antagonists known to date.

Early in the 1980s, Anis et al.[15] showed that the dissociative anaesthetics ketamine and phencyclidine block the NMDA response in a non-competitive way. Later, Wong et al.[16] presented with MK-801 the most potent non-competitive NMDA antagonist so far. These antagonists display a marked use-dependency, thus, it appears that they inhibit the NMDA response by binding preferentially to an agonist-activated state of the receptor ion-channel complex. In this respect, it is interesting to note that already in 1965, in our institute, a structurally similar compound labelled 100-131, was developed, because of its anticonvulsant properties. However, at that time the concept of NMDA-channel blockers was completely unknown. Even more recently, Johnson and Ascher [17] discovered that micromolar concentrations of glycine facilitate the action of NMDA, and from electrophysiological experiments [18], it seems that occupation of the glycine site at the NMDA-receptor complex is necessary to open the associated. ion channel. Also, it has been found that polyamines like spermine or spermidine, which are endogenously present in the brain, modulate the NMDA receptor [19].

\section{Therapeutic Potential of NMDA Antagonist}

Due to the relative novelty of the research area, there is no practical experience yet for the clinical application of highly selective, competitive NMDA-receptor antagonists. NMDA-receptor antagonists possess anticonvulsant activity and have been shown to be effective in several epilepsy models. Thus, SDZ EAA-494 (D-CPPene, see Scheme) actively protects DBA/2 mice from soundinduced seizures, and in a primate model, protects photosensitive baboons from photically induced myoclonus [20]. The treatment of epileptic seizures in man, up to now, has relied mostly on pharmacological enhancement of inhibitory neurotransmission. Therefore, by inhibiting excitatory pathways, this may offer a new way for treating epileptic patients. Already many years ago, it was discovered that glutamic acid can act as a neurotoxin [21]. Since it is the most abundant amino acid in the brain, it was proposed that glutamate might play a role in neurodegenerative diseases. In cell cultures as well as in rodent brains, it was shown that NMDA antagonists could prevent cell death induced by anoxia [22]. It appears that, due to a general metabolic failure caused by the lack of oxygen, glutamic acid is no longer removed from the synaptic cleft. The persistent excessive stimulation of NMDA receptors leads then probably to a calcium overload inside the neurones and to their subsequent death [23]. Therefore, NMDA antagonists may have beneficial effects in stroke victims, where oxygen supply to the affected brain area is impaired . Indeed, SDZ EAA494 (D-CPPene) as well as MK-801 have been found to reduce the infarct size in a stroke model [24][25]. Potentially beneficial effects of NMDA antagonists in other neurodegenerative diseases as well as the investigation of the therapeutic potential in other areas will depend on initial clinical trials.
The author whishes to thank his colleagues Drs. $B$. Aebischer, D. Lowe. P.L. Herrling, and B. Roy for their discussions, for carefully reading the manuscript and for their valuable input.

Received: November 16, 1990

[1] T. Hayashi, Keio I. Med. 1954, 3, 1831

[2] D.R. Curtis, J.W. Phillis, J.C. Watkins, J. Physiol. $1960,150,656$.

[3] J.Davies, J.C. Watkins, J.Physiol. 1979, 297,621

[4] H. McLennan, D. Lodge, Brain Res. 1979, 169, 83.

[5] P. Krogsguard-Larsen. T. Honore, J.J. Hansen, D.R. Curtis, D. Lodge, Natme (London) 1980, 281,64 .

[6] F. Sladezek, J.P. Pin, M. Recasens, J. Bockaert, S. Weiss, Nature (London) 1985, 317, 717.

[7] J.C. Watkins, P. Krogsgaard-Larsen, T. Honore, Trends Pharmcol.Sci. 1990, /1, 25; A.B. Young, G.E. Fagg, ibid. 1990, II, I26; J.F. MacDonald, L.M. Novak, ibid, 1990, $M, 167$; P.M. Headley, S. Grillner, ihid. 1990, 11, 205; M.L. Mayer, R.J. Miller, ibid. 1990, 11, 254; G.L. Collingridge, W. Singer, ibid. 1990, $I 1,290$.

[8] K.Q. Do, P.L. Herrling, P. Streit, W.A. Turski, M. Cuenod, J. Neurosci. 1986, 6, 2226.

[9] J.D. Davies, J.C. Watkins, Brain Res. 1977, /30, 364.

[10] R.H. Evans, A.A. Francis, A.W. Jones, D.A.S. Smith, J.C. Watkins, Br.J. Pharmacol. 1982, 75, 65.

[11] J.C. Watkins. A.W. Jones, UK Patent Application, 1985, GB 2157 685A, HMSO, London.

[12] B. Aebischer, P. Frcy, H.P. Haerter, P.L. Herrling, W. Mueller, H.J. Olverman, J.C. Watkins, $\mathrm{Hel}$, Chim. Acta 1989, 72, 1043.

[13] J. Lehmann, A.G. Chapman, B.S. Meldrum, A. Hutchinson, C. Tsai, P.L. Wood, Eur. I. Pharmacol. 1988, 154, 89.

[14] G.E. Fagg, M.F. Pozza, H.-R. Olpe, F. Brugger, P. Baumann, H. Bittiger, M. Schmutz, C. Angst, D. Brundish, H. Allgeier, R. Heckendorn, J.G. Dingwall, Br. J. Pharmarol. 1989, 97, 582P.

[15] N.A. Anis, S.C. Berry, N.R. Burton, D. Lodge, Br.J. Pharmacol. 1983, 79, 565.

[16] E.H.F. Wong, J.A. Kemp, T. Priestley, A.R. Knight, G.N. Woodruff, L.L. Iversen, Proc. Natl. Acad. Sci. U.S.A. 1986, 83, 7104.

[17] J.W. Johnson, P. Ascher, Nalure (Londen) 1987. $325,529$.

[18] N.W.Kleckner, R. Dingledine, Science 1988,241, 835 .

[19] R.W. Ransom, N.L. Stec,J.Neurochem. 1988,5I, 830.

[20] S. Patel, A.G. Chapman, J.L. Graham, B.S. Meldrum, P. Frey, Epilepsy Res. 1990 , in press.

[21] J.W. Olney, Science 1969, 164, 719.

[22] R.P. Simon, J.H. Swan, T. Griffiths, B.S. Meldrum, Science 1984, 226,850.

[23] S.M. Rothmun, J.W. Olney, Trends Neurosidi. 1987, 10, 299.

[24] M. Chen, R. Bullock, D.I. Graham, P. Frey, D. Lowe, J. McCulloch, Annals Neurol., in press.

[25] E. Özyurt, D.I. Graham, G.N. Woodruff, J. McCulloch, J. Cereb. Blond Flow Metab. 1988, \&, 138. 


\section{Zum 100. Geburtstag von Prof. Emile Cherbuliez}

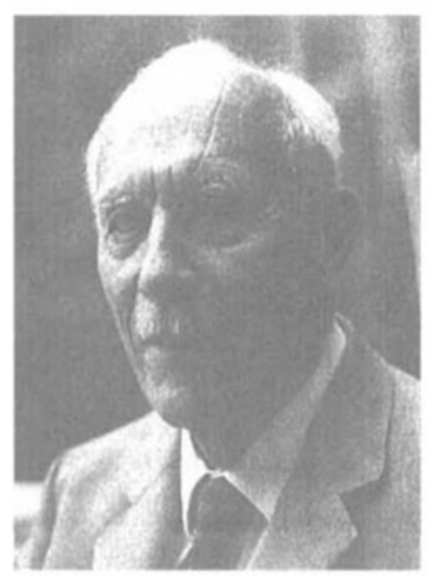

Nach Prof. F. Fichter, der die Geschicke der Zeitschrift Helvetica Chimica Acta von ihrem Anbeginn 1918 bis zum Jahr 1948 leitete, übernahm Prof. Emile Cherbuliez das Amt eines Präsidenten des Redaktionskomitees, das zum damaligen Zeitpunkt noch mit demjenigen des allein verantwortlichen Redaktors zusammenfiel. Er gab dieses Amt 1971 weiter und verstarb 1985, hochbetagt im Alter von 94 Jah-

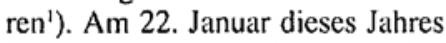
hätte er seinen 100 . Geburtstag feiern können.

Vielen, vornehmlich den älteren Fachkollegen, ist Emile Cherbuliez sowohl durch seine liebenswerte und ausserordentliche Persönlickeit, als auch durch seine aufopfernde Tätigkeit im Dienste der Schweizerischen Chemie im Gedächtnis. Als gestrengerSpiritus rector der Helvetica Chimica Acta, der durch seine Forderung eines konzisen und rigorosen Stils die Schreibgewohnheiten seiner Autoren geformt hat, und als langjähriges, prägendes Mitglied des Vorstands der Schweizerischen Chemischen Gesellschaft, war er allen ein Vorbild. Seine umfassende Bildung, insbesondere seine Pflege der Geschichte der Chemie ${ }^{2}$ ), machten ihn - neben seinen wissenschaftlichen Kenntnissen - zu einem faszinierenden Gesprächspartner.

Das Redaktionskomitee der $\mathrm{Hel}$ vetica Chimica Acta, möchte deshalb nochmals ${ }^{3}$ ) die Gelegenheit ergreifen, seiner in Verehrung und grosser Dankbarkeit zu gedenken.

\section{E. Giovannini \\ E. Heilbronner}

Heiv. Chim. Acta 1986, 69, 1.

Helv. Chim. Acta 1978, 61,937.

3) Helv. Chim. Acta 1966, 49, I; ihid. 1971, 54, 1: Heid. Chim. Acta $1981,64,1$.
Polymer-Gruppe der Schweiz

Groupe Suisse des Polymères

Gruppo Svizzero dei Polimeri

\section{Frühjahrstagung der Polymer-Gruppe der Schweiz (PGS)}

Industrielle $\mathrm{F}+\mathrm{E}$-Tätigkeiten auf dem Polymergebiet in der Schweiz

Dienstag, 19. März 1991

Landhaus Solothurn

Die Polymer-Gruppe der Schweiz (PGS) setzt ihren Vortragszyklus über «Industrielle F+E-Tütigkeiten auf dem Polymer-Gebiet in der Schweiz» fort, wobei den in der Schweizt tätigen Firmen die Mög-

Schweizerische Chemische Gesellschaft Schweizerischer Chemiker-Verband

\section{Frühjahrsversammlung} in Basel

Freitag, den 15. März 1991

Zentrum für Lehre und Forschung, Kantonsspital Basel

Hebelstr. 20, Grosser Hörsaal ZLF

'Free Radicals: From Molecules to Biochemical Processes'

09.20 Geschäftlicher Teil/ Partie administrative Wissenschaftlicher Teil/ Partie scientifique

10.00 N.A. Porter, Duke University, Durham, USA: 'Stereochemical Control of Free Radical Additions, Oligomerizations, and Polymerizations'

11.00 Pause

11.30 Verleihung des WernerPreises 1991 der Schweizerischen Chemischen $\mathrm{Ge}$ sellschaft

11.45 J.T. Groves, Princeton University, Princeton, USA: 'Catalytic Asymmetric Hy- droxylation with Metalloporphyrin Complexes

12.45 Mittagspause/Pause de midi 14.15 K.U. Ingold, National Research Council, Ottawa, Canada: 'Rate Processes in Complex Systems: Studies on Cytochrom P-4.50 and Vitamin E'

15.15 J. Rétey, Universität Karlsruhe, Karlsruhe, Deutschland: "Generation and Control of Radical Intermediates by Enzymes. The Role of Coenzyme $\mathrm{B}_{12}$,

16.15 Pause

16.45 S. Hanessian, Université de Montreal, Canada: 'The Challenge of Stereocontrolled Ring Formation by Free Radical Reactions'

17.45 Schluss der Versammlung/ Clôture de la séance

Information/Kontakt: Dr.E.Zass, Sekretär SCG,ETHZürich, Universitätstr. 16, CH-8092 Zürich

\section{Schweizerische Chemische Gesellschaft}

Société Suisse du Chimie

\section{Protokoll}

der Herbstversammlung der Schweizerischen Chemischen Gesellschaft vom 19. Oktober 1990 in Bern

\section{A. Geschäftlicher Teil}

Der Präsident eröffnete die Sitzung um $8.30 \mathrm{Uhr}$. stellen.

An der dritten Tagung im Rahmen dieses Zyklus werden die Firmen:

- BPChemicals(Suisse) S.A., Genf - Dow Europe S.A., Horgen

- Gurit-Essex AG, Freienbach

- Sarna Kunststoff AG, Sarnen über ihr Tätigkeitsgebiet berichten. Weitere Auskünfte und Anmeldungen beim Sekretariat der PGS am Institut für Polymere der ETHZ, Universitätstrasse 6, 8092 Zürich, Telefon 012563058.
1. Das Protokoll der Frühjahrsversammlung vom 16. März 1990 in Zürich wurde mit einer Korrektur genehmigt: Im Anne.r 2 unter B) «Details...», Punkt 4 ist in der rechten Kolonne für 1988 in der 5. Zeile von unten SFr. 3'000.- durch 1'500.- zu ersetzen.

2. Die diesjährige Herbstversammlung bietet ein umfang. reicheres Programm als bisher unter Beteiligung des Comité
Suisse de Chimic Analytique und der Schweiz. Gesellschaft für Instrumentalanalytik und Mikrochemie (vgl. Teil B). Die Frühjahrsversammlung 1991 wird am 15. März in Basel im Zentrum für Lehre und Forschung des Kantonsspitals durchgeführt werden. Als Vortragende zum Thema 'Free Radicals: From Molecules to Biochemical Processes' konnten Prof. J.T. Groves (Princeton Univ., USA), Prof. S. Hanessian (Univ. de Montreal, Canada), Prof. K.U. Ingold (Natl. Res. Council, Ottawa, Canada), Prof. N.A. Porter (Duke Univ., Durham USA), und Prof. J. Rétey (Univ. Karlsruhe) gewonnen werden.

3. Die Mitgliedsheiträge für 1991 bleiben unverändert; pensio- 


\section{Zum 100. Geburtstag von Prof. Emile Cherbuliez}

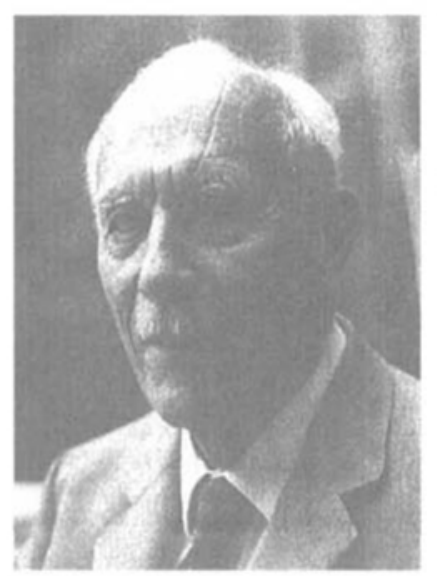

Nach Prof. F. Fichter, der die Geschicke der Zeitschrift Helvetica Chimica Acta von ihrem Anbeginn 1918 bis zum Jahr 1948 leitete, übernahm Prof. Emile Cherbuliez das Amt eines Präsidenten des Redaktionskomitees, das zum damaligen Zeitpunkt noch mit demjenigen des allein verantwortlichen Redaktors zusammenfiel. Er gab dieses Amt 1971 weiter und verstarb 1985, hochbetagt im Alter von 94 Jah-

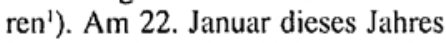
hätte er seinen 100 . Geburtstag feiern können.

Vielen, vornehmlich den älteren Fachkollegen, ist Emile Cherbuliez sowohl durch seine liebenswerte und ausserordentliche Persönlickeit, als auch durch seine aufopfernde Tätigkeit im Dienste der Schweizerischen Chemie im Gedächtnis. Als gestrengerSpiritus rector der Helvetica Chimica Acta, der durch seine Forderung eines konzisen und rigorosen Stils die Schreibgewohnheiten seiner Autoren geformt hat, und als langjähriges, prägendes Mitglied des Vorstands der Schweizerischen Chemischen Gesellschaft, war er allen ein Vorbild. Seine umfassende Bildung, insbesondere seine Pflege der Geschichte der Chemie ${ }^{2}$ ), machten ihn - neben seinen wissenschaftlichen Kenntnissen - zu einem faszinierenden Gesprächspartner.

Das Redaktionskomitee der $\mathrm{Hel}$ vetica Chimica Acta, möchte deshalb nochmals ${ }^{3}$ ) die Gelegenheit ergreifen, seiner in Verehrung und grosser Dankbarkeit zu gedenken.

\section{E. Giovannini \\ E. Heilbronner}

Heiv. Chim. Acta 1986, 69, 1.

Helv. Chim. Acta 1978, 61,937.

3) Helv. Chim. Acta 1966, 49, I; ihid. 1971, 54, 1: Heid. Chim. Acta $1981,64,1$.
Polymer-Gruppe der Schweiz

Groupe Suisse des Polymères

Gruppo Svizzero dei Polimeri

\section{Frühjahrstagung der Polymer-Gruppe der Schweiz (PGS)}

Industrielle $\mathrm{F}+\mathrm{E}$-Tätigkeiten auf dem Polymergebiet in der Schweiz

Dienstag, 19. März 1991

Landhaus Solothurn

Die Polymer-Gruppe der Schweiz (PGS) setzt ihren Vortragszyklus über «Industrielle F+E-Tütigkeiten auf dem Polymer-Gebiet in der Schweiz» fort, wobei den in der Schweizt tätigen Firmen die Mög-

Schweizerische Chemische Gesellschaft Schweizerischer Chemiker-Verband

\section{Frühjahrsversammlung} in Basel

Freitag, den 15. März 1991

Zentrum für Lehre und Forschung, Kantonsspital Basel

Hebelstr. 20, Grosser Hörsaal ZLF

'Free Radicals: From Molecules to Biochemical Processes'

09.20 Geschäftlicher Teil/ Partie administrative Wissenschaftlicher Teil/ Partie scientifique

10.00 N.A. Porter, Duke University, Durham, USA: 'Stereochemical Control of Free Radical Additions, Oligomerizations, and Polymerizations'

11.00 Pause

11.30 Verleihung des WernerPreises 1991 der Schweizerischen Chemischen $\mathrm{Ge}$ sellschaft

11.45 J.T. Groves, Princeton University, Princeton, USA: 'Catalytic Asymmetric Hy- droxylation with Metalloporphyrin Complexes

12.45 Mittagspause/Pause de midi 14.15 K.U. Ingold, National Research Council, Ottawa, Canada: 'Rate Processes in Complex Systems: Studies on Cytochrom P-4.50 and Vitamin E'

15.15 J. Rétey, Universität Karlsruhe, Karlsruhe, Deutschland: "Generation and Control of Radical Intermediates by Enzymes. The Role of Coenzyme $\mathrm{B}_{12}$,

16.15 Pause

16.45 S. Hanessian, Université de Montreal, Canada: 'The Challenge of Stereocontrolled Ring Formation by Free Radical Reactions'

17.45 Schluss der Versammlung/ Clôture de la séance

Information/Kontakt: Dr.E.Zass, Sekretär SCG,ETHZürich, Universitätstr. 16, CH-8092 Zürich

\section{Schweizerische Chemische Gesellschaft}

Société Suisse du Chimie

\section{Protokoll}

der Herbstversammlung der Schweizerischen Chemischen Gesellschaft vom 19. Oktober 1990 in Bern

\section{A. Geschäftlicher Teil}

Der Präsident eröffnete die Sitzung um $8.30 \mathrm{Uhr}$. stellen.

An der dritten Tagung im Rahmen dieses Zyklus werden die Firmen:

- BPChemicals(Suisse) S.A., Genf - Dow Europe S.A., Horgen

- Gurit-Essex AG, Freienbach

- Sarna Kunststoff AG, Sarnen über ihr Tätigkeitsgebiet berichten. Weitere Auskünfte und Anmeldungen beim Sekretariat der PGS am Institut für Polymere der ETHZ, Universitätstrasse 6, 8092 Zürich, Telefon 012563058.
1. Das Protokoll der Frühjahrsversammlung vom 16. März 1990 in Zürich wurde mit einer Korrektur genehmigt: Im Anne.r 2 unter B) «Details...», Punkt 4 ist in der rechten Kolonne für 1988 in der 5. Zeile von unten SFr. 3'000.- durch 1'500.- zu ersetzen.

2. Die diesjährige Herbstversammlung bietet ein umfang. reicheres Programm als bisher unter Beteiligung des Comité
Suisse de Chimic Analytique und der Schweiz. Gesellschaft für Instrumentalanalytik und Mikrochemie (vgl. Teil B). Die Frühjahrsversammlung 1991 wird am 15. März in Basel im Zentrum für Lehre und Forschung des Kantonsspitals durchgeführt werden. Als Vortragende zum Thema 'Free Radicals: From Molecules to Biochemical Processes' konnten Prof. J.T. Groves (Princeton Univ., USA), Prof. S. Hanessian (Univ. de Montreal, Canada), Prof. K.U. Ingold (Natl. Res. Council, Ottawa, Canada), Prof. N.A. Porter (Duke Univ., Durham USA), und Prof. J. Rétey (Univ. Karlsruhe) gewonnen werden.

3. Die Mitgliedsheiträge für 1991 bleiben unverändert; pensio- 


\section{Zum 100. Geburtstag von Prof. Emile Cherbuliez}

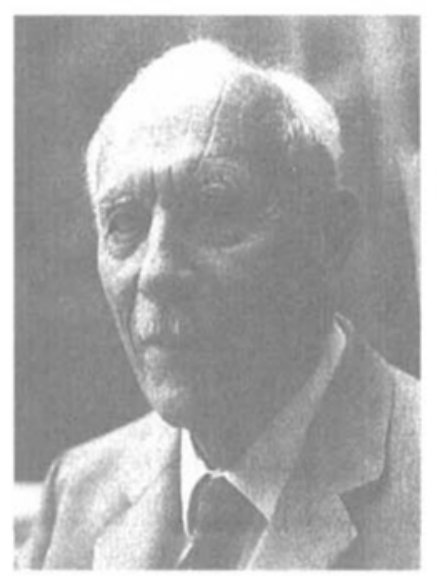

Nach Prof. F. Fichter, der die Geschicke der Zeitschrift Helvetica Chimica Acta von ihrem Anbeginn 1918 bis zum Jahr 1948 leitete, übernahm Prof. Emile Cherbuliez das Amt eines Präsidenten des Redaktionskomitees, das zum damaligen Zeitpunkt noch mit demjenigen des allein verantwortlichen Redaktors zusammenfiel. Er gab dieses Amt 1971 weiter und verstarb 1985, hochbetagt im Alter von 94 Jah-

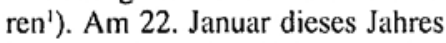
hätte er seinen 100 . Geburtstag feiern können.

Vielen, vornehmlich den älteren Fachkollegen, ist Emile Cherbuliez sowohl durch seine liebenswerte und ausserordentliche Persönlickeit, als auch durch seine aufopfernde Tätigkeit im Dienste der Schweizerischen Chemie im Gedächtnis. Als gestrengerSpiritus rector der Helvetica Chimica Acta, der durch seine Forderung eines konzisen und rigorosen Stils die Schreibgewohnheiten seiner Autoren geformt hat, und als langjähriges, prägendes Mitglied des Vorstands der Schweizerischen Chemischen Gesellschaft, war er allen ein Vorbild. Seine umfassende Bildung, insbesondere seine Pflege der Geschichte der Chemie ${ }^{2}$ ), machten ihn - neben seinen wissenschaftlichen Kenntnissen - zu einem faszinierenden Gesprächspartner.

Das Redaktionskomitee der $\mathrm{Hel}$ vetica Chimica Acta, möchte deshalb nochmals ${ }^{3}$ ) die Gelegenheit ergreifen, seiner in Verehrung und grosser Dankbarkeit zu gedenken.

\section{E. Giovannini \\ E. Heilbronner}

Heiv. Chim. Acta 1986, 69, 1.

Helv. Chim. Acta 1978, 61,937.

3) Helv. Chim. Acta 1966, 49, I; ihid. 1971, 54, 1: Heid. Chim. Acta $1981,64,1$.
Polymer-Gruppe der Schweiz

Groupe Suisse des Polymères

Gruppo Svizzero dei Polimeri

\section{Frühjahrstagung der Polymer-Gruppe der Schweiz (PGS)}

Industrielle $\mathrm{F}+\mathrm{E}$-Tätigkeiten auf dem Polymergebiet in der Schweiz

Dienstag, 19. März 1991

Landhaus Solothurn

Die Polymer-Gruppe der Schweiz (PGS) setzt ihren Vortragszyklus über «Industrielle F+E-Tütigkeiten auf dem Polymer-Gebiet in der Schweiz» fort, wobei den in der Schweizt tätigen Firmen die Mög-

Schweizerische Chemische Gesellschaft Schweizerischer Chemiker-Verband

\section{Frühjahrsversammlung} in Basel

Freitag, den 15. März 1991

Zentrum für Lehre und Forschung, Kantonsspital Basel

Hebelstr. 20, Grosser Hörsaal ZLF

'Free Radicals: From Molecules to Biochemical Processes'

09.20 Geschäftlicher Teil/ Partie administrative Wissenschaftlicher Teil/ Partie scientifique

10.00 N.A. Porter, Duke University, Durham, USA: 'Stereochemical Control of Free Radical Additions, Oligomerizations, and Polymerizations'

11.00 Pause

11.30 Verleihung des WernerPreises 1991 der Schweizerischen Chemischen $\mathrm{Ge}$ sellschaft

11.45 J.T. Groves, Princeton University, Princeton, USA: 'Catalytic Asymmetric Hy- droxylation with Metalloporphyrin Complexes

12.45 Mittagspause/Pause de midi 14.15 K.U. Ingold, National Research Council, Ottawa, Canada: 'Rate Processes in Complex Systems: Studies on Cytochrom P-4.50 and Vitamin E'

15.15 J. Rétey, Universität Karlsruhe, Karlsruhe, Deutschland: "Generation and Control of Radical Intermediates by Enzymes. The Role of Coenzyme $\mathrm{B}_{12}$,

16.15 Pause

16.45 S. Hanessian, Université de Montreal, Canada: 'The Challenge of Stereocontrolled Ring Formation by Free Radical Reactions'

17.45 Schluss der Versammlung/ Clôture de la séance

Information/Kontakt: Dr.E.Zass, Sekretär SCG,ETHZürich, Universitätstr. 16, CH-8092 Zürich

\section{Schweizerische Chemische Gesellschaft}

Société Suisse du Chimie

\section{Protokoll}

der Herbstversammlung der Schweizerischen Chemischen Gesellschaft vom 19. Oktober 1990 in Bern

\section{A. Geschäftlicher Teil}

Der Präsident eröffnete die Sitzung um $8.30 \mathrm{Uhr}$. stellen.

An der dritten Tagung im Rahmen dieses Zyklus werden die Firmen:

- BPChemicals(Suisse) S.A., Genf - Dow Europe S.A., Horgen

- Gurit-Essex AG, Freienbach

- Sarna Kunststoff AG, Sarnen über ihr Tätigkeitsgebiet berichten. Weitere Auskünfte und Anmeldungen beim Sekretariat der PGS am Institut für Polymere der ETHZ, Universitätstrasse 6, 8092 Zürich, Telefon 012563058.
1. Das Protokoll der Frühjahrsversammlung vom 16. März 1990 in Zürich wurde mit einer Korrektur genehmigt: Im Anne.r 2 unter B) «Details...», Punkt 4 ist in der rechten Kolonne für 1988 in der 5. Zeile von unten SFr. 3'000.- durch 1'500.- zu ersetzen.

2. Die diesjährige Herbstversammlung bietet ein umfang. reicheres Programm als bisher unter Beteiligung des Comité
Suisse de Chimic Analytique und der Schweiz. Gesellschaft für Instrumentalanalytik und Mikrochemie (vgl. Teil B). Die Frühjahrsversammlung 1991 wird am 15. März in Basel im Zentrum für Lehre und Forschung des Kantonsspitals durchgeführt werden. Als Vortragende zum Thema 'Free Radicals: From Molecules to Biochemical Processes' konnten Prof. J.T. Groves (Princeton Univ., USA), Prof. S. Hanessian (Univ. de Montreal, Canada), Prof. K.U. Ingold (Natl. Res. Council, Ottawa, Canada), Prof. N.A. Porter (Duke Univ., Durham USA), und Prof. J. Rétey (Univ. Karlsruhe) gewonnen werden.

3. Die Mitgliedsheiträge für 1991 bleiben unverändert; pensio- 


\section{Zum 100. Geburtstag von Prof. Emile Cherbuliez}

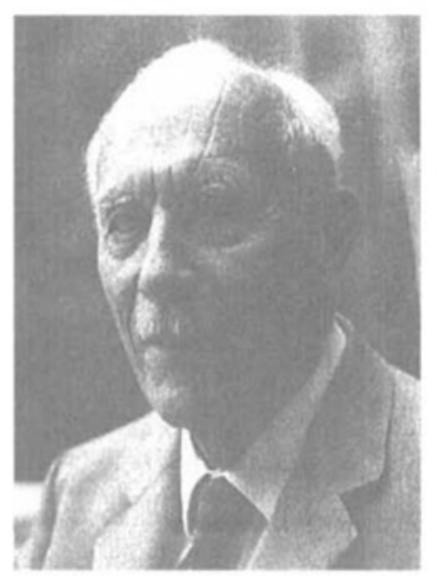

Nach Prof. F. Fichter, der die Geschicke der Zeitschrift Helvetica Chimica Acta von ihrem Anbeginn 1918 bis zum Jahr 1948 leitete, übernahm Prof. Emile Cherbuliez das Amt eines Präsidenten des Redaktionskomitees, das zum damaligen Zeitpunkt noch mit demjenigen des allein verantwortlichen Redaktors zusammenfiel. Er gab dieses Amt 1971 weiter und verstarb 1985, hochbetagt im Alter von 94 Jah-

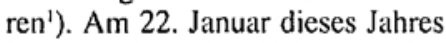
hätte er seinen 100 . Geburtstag feiern können.

Vielen, vornehmlich den älteren Fachkollegen, ist Emile Cherbuliez sowohl durch seine liebenswerte und ausserordentliche Persönlickeit, als auch durch seine aufopfernde Tätigkeit im Dienste der Schweizerischen Chemie im Gedächtnis. Als gestrengerSpiritus rector der Helvetica Chimica Acta, der durch seine Forderung eines konzisen und rigorosen Stils die Schreibgewohnheiten seiner Autoren geformt hat, und als langjähriges, prägendes Mitglied des Vorstands der Schweizerischen Chemischen Gesellschaft, war er allen ein Vorbild. Seine umfassende Bildung, insbesondere seine Pflege der Geschichte der Chemie ${ }^{2}$ ), machten ihn - neben seinen wissenschaftlichen Kenntnissen - zu einem faszinierenden Gesprächspartner.

Das Redaktionskomitee der $\mathrm{Hel}$ vetica Chimica Acta, möchte deshalb nochmals ${ }^{3}$ ) die Gelegenheit ergreifen, seiner in Verehrung und grosser Dankbarkeit zu gedenken.

\section{E. Giovannini \\ E. Heilbronner}

Heiv. Chim. Acta 1986, 69, 1.

Helv. Chim. Acta 1978, 61,937.

3) Helv. Chim. Acta 1966, 49, I; ihid. 1971, 54, 1: Heid. Chim. Acta $1981,64,1$.
Polymer-Gruppe der Schweiz

Groupe Suisse des Polymères

Gruppo Svizzero dei Polimeri

\section{Frühjahrstagung der Polymer-Gruppe der Schweiz (PGS)}

Industrielle $\mathrm{F}+\mathrm{E}$-Tätigkeiten auf dem Polymergebiet in der Schweiz

Dienstag, 19. März 1991

Landhaus Solothurn

Die Polymer-Gruppe der Schweiz (PGS) setzt ihren Vortragszyklus über «Industrielle F+E-Tütigkeiten auf dem Polymer-Gebiet in der Schweiz» fort, wobei den in der Schweizt tätigen Firmen die Mög-

Schweizerische Chemische Gesellschaft Schweizerischer Chemiker-Verband

\section{Frühjahrsversammlung} in Basel

Freitag, den 15. März 1991

Zentrum für Lehre und Forschung, Kantonsspital Basel

Hebelstr. 20, Grosser Hörsaal ZLF

'Free Radicals: From Molecules to Biochemical Processes'

09.20 Geschäftlicher Teil/ Partie administrative Wissenschaftlicher Teil/ Partie scientifique

10.00 N.A. Porter, Duke University, Durham, USA: 'Stereochemical Control of Free Radical Additions, Oligomerizations, and Polymerizations'

11.00 Pause

11.30 Verleihung des WernerPreises 1991 der Schweizerischen Chemischen $\mathrm{Ge}$ sellschaft

11.45 J.T. Groves, Princeton University, Princeton, USA: 'Catalytic Asymmetric Hy- droxylation with Metalloporphyrin Complexes

12.45 Mittagspause/Pause de midi 14.15 K.U. Ingold, National Research Council, Ottawa, Canada: 'Rate Processes in Complex Systems: Studies on Cytochrom P-4.50 and Vitamin E'

15.15 J. Rétey, Universität Karlsruhe, Karlsruhe, Deutschland: "Generation and Control of Radical Intermediates by Enzymes. The Role of Coenzyme $\mathrm{B}_{12}$,

16.15 Pause

16.45 S. Hanessian, Université de Montreal, Canada: 'The Challenge of Stereocontrolled Ring Formation by Free Radical Reactions'

17.45 Schluss der Versammlung/ Clôture de la séance

Information/Kontakt: Dr.E.Zass, Sekretär SCG,ETHZürich, Universitätstr. 16, CH-8092 Zürich

\section{Schweizerische Chemische Gesellschaft}

Société Suisse du Chimie

\section{Protokoll}

der Herbstversammlung der Schweizerischen Chemischen Gesellschaft vom 19. Oktober 1990 in Bern

\section{A. Geschäftlicher Teil}

Der Präsident eröffnete die Sitzung um $8.30 \mathrm{Uhr}$. stellen.

An der dritten Tagung im Rahmen dieses Zyklus werden die Firmen:

- BPChemicals(Suisse) S.A., Genf - Dow Europe S.A., Horgen

- Gurit-Essex AG, Freienbach

- Sarna Kunststoff AG, Sarnen über ihr Tätigkeitsgebiet berichten. Weitere Auskünfte und Anmeldungen beim Sekretariat der PGS am Institut für Polymere der ETHZ, Universitätstrasse 6, 8092 Zürich, Telefon 012563058.
1. Das Protokoll der Frühjahrsversammlung vom 16. März 1990 in Zürich wurde mit einer Korrektur genehmigt: Im Anne.r 2 unter B) «Details...», Punkt 4 ist in der rechten Kolonne für 1988 in der 5. Zeile von unten SFr. 3'000.- durch 1'500.- zu ersetzen.

2. Die diesjährige Herbstversammlung bietet ein umfang. reicheres Programm als bisher unter Beteiligung des Comité
Suisse de Chimic Analytique und der Schweiz. Gesellschaft für Instrumentalanalytik und Mikrochemie (vgl. Teil B). Die Frühjahrsversammlung 1991 wird am 15. März in Basel im Zentrum für Lehre und Forschung des Kantonsspitals durchgeführt werden. Als Vortragende zum Thema 'Free Radicals: From Molecules to Biochemical Processes' konnten Prof. J.T. Groves (Princeton Univ., USA), Prof. S. Hanessian (Univ. de Montreal, Canada), Prof. K.U. Ingold (Natl. Res. Council, Ottawa, Canada), Prof. N.A. Porter (Duke Univ., Durham USA), und Prof. J. Rétey (Univ. Karlsruhe) gewonnen werden.

3. Die Mitgliedsheiträge für 1991 bleiben unverändert; pensio- 
nierte Mitglieder geniessen mit einem entsprechenden Vermerks bei der Einzahlung die gleiche Vergünstigung wie Studenten.

4. Wahlen für Amtsperiode $1991-$ 92. Für weitere zwei Jahre werden durch Akklamation bestätigt: Dr. D. Hauser (Sandoz Pharma AG, Basel) als Beisitzer, Prof. J. Wirz (Univ. Basel) als Rechnungsrevisor.

Damit setzl sich der Vorstand für 1991-92 wie folgt zusammen:

Präsident:

W. von Philipsborn, Zürich

Vizepräsident:

A.E. Merbach, Lausanne

Schatzmeister:

J. Kalvoda, Basel

Altpräsidenten:

T. Gäumann, Lausanne

G. Ohloff, Genf

A. Eschenmoser, Zürich

Beisitzer:

D. Hauser, Basel

D. Bellus, Basel

K. Müller, Basel

D. Seebach, Zürich

Vertreter des Redaktionskomitees Helvetica Chimica Acta:

E. Heilbronner, Herrliberg

L.M. Venanzi, Zürich

H.-J. Hansen, Zürich

Ch. Tamm, Basel

Redaktor Helv. Chim. Acta

M.V. Kısakürek, Basel

Rechnungsrevisoren:

J. Wirz, Basel

P. Zeller, Basel

Sekretïr:

E. Zass, Zürich

Das Redaktionskomitee Helvetica Chimica Acta hat folgende Mitglieder:

Präsident:

E. Heilbronner, Herrliberg

Vizepräsidenten:

L.M. Venanzi, Zürich

H.-J. Hansen, Zürich

Ch. Tamm, Basel

Beisitzer:

H.-B. Buirgi, Bern

H. Heimgartner, Zürich

M. Hesse, Zürich

A. Kaiser, Basel

A.E. Merbach, Lausanne

K. Müller, Basel

W. Oppolzer, Genf

D. Seebach, Zürich

A. Vasella, Zürich

J. Wirz, Basel

Redaktor:

M.V. Kısakürek, Basel

\section{Werner-Preis}

Der Vorstand teilt den Mitgliedern der Schweizerischen Chemischen Gesellschaft mit, dass dieser Preis an der Frühjahrsversammlung 1992 nach den Bestimmungen der
5. Der Präsident informiert über den Fortgang der Kooperation von SCG und SChV (gemeinsam veranstaltete Tagungen, gemeinsame technische Redaktion von Helvetica Chimica Acta und Chimia) und über den Stand der Fusionsvorbereitungen beiderGesellschaften. Ein Entwurf für Struktur und Statuten der neuen Gesellschaft und ihrer Sektionen sowie ein 12-PunkteProgramm für neue Leistungen liegen vor; die Mitglieder werden in einem gemeinsamen Kommunique im Heft 12/90 der Chimia informiert.

6. Varia: Keine Wortmeldung Schluss der Sitzung: 8.55 Uhr

\section{B. Wissenschaftlicher Teil}

Das Programm enthielt den Vortrag des Werner-Preisträgers 1990 Dr. H. Frei (Univ. of California, Berkeley, USA) 'Chemistry with red and near infrared light', das Symposium 'Recent Developments in Organometallic Chemistry and Homogeneous Catalysis' mit Vorträgen von H. Berke (Univ. Zürich) 'The tuning of organometallic insertion reactions', $G$. Süss-Fink (Univ. de Neuchâtel) 'Anionic ruthenium clusters as hydroformylation catalysts Recent and previous results', $W . I$. Evans (Univ. of California, Irvine/ USA) 'Chemistry within a dynamic tetracyclopentadienyl cavity? Some recent results in organolanthanide chemistry', T. Hayashi (Hokkaido Univ., Sapporo/Japan)'Asymmetric synthesis catalyzed by chiral ferrocenylphosphine - transition metal complexes', und das Seminar 'Analytische Chemie' des erstmals als Gast an der Herbstversammlung teilnehmenden Comité Suisse de Chimie Analytique mit 10 Vorträgen und 34 Postem. Die Sektion Medizinische Chemie organisierte 13 Vorträge und Kurzmitteilungen, weitere Kurzmitteilungen wurden in Organischer Chemie (insgesamt 36 in zwei Parallelsessionen), Physikalischer Chemie (11) und im $\mathrm{Mi}$ nisymposium 'Computational Chemistry' (7) präsentiert. Die Anorganische Chemie und Koordinationschemie waren ausser dem erwähnten Minisymposium noch mit 47 Postern vertreten.

Der Präsident:

Prof. W. von Philipsborn

Der Sekretär:

Dr. E. Zass

Artikel 23-26 der Statuten verliehen werden kann:

«Der Preis mit Medaille kann in jährlichem Turnus an schweizerische oder in der Schweiz tätige, aus- ländische Nachwuchswissenschafter für ausgezeichnete Forschungsarbeiten auf dem Gebiete der Chemie verliehen werden. Pro Jahr werden in der Regel höchstens zwei Werner-Preise erteilt. Die Auswahl der Preisträger hat sich nicht auf Kandidaten zu beschränken, die an einer Hochschule tätig sind. Ausnahmsweise kann der Preis auch an ältere Forscher verliehen werden.»

. Vorschläge und Bewerbungen sind mit den nachstehend aufgeführten Belegen dem Präsidenten der SCG bis zum 31. Mai 1991 einzureichen.

\section{Prix Werner}

Le Comité informe les membres de la Société Suisse de Chimie que ce prix peut être attribué à l'assemblée de printemps 1992 conformément aux conditions définies dans les articles 23-26 des statuts:

«Le prix, qui est doté d'une médaille, peut être attribué annuellement à des jeunes chercheurs suisses, ou étrangers travaillant en Suisse, pour des travaux de recherche de haut niveau dans le domaine de la chimie. Dans la règle, pas plus de deux prix Werner ne sont décernés par année. Le choix des candidats à ce prix ne doit pas se limiter à ceux qui travaillent dans une université Exceptionellement le prix peut être attribué à un chercheur âgé.»

a) Antrag mit Begründung

b) Curriculum vitae

c) Publikationsliste

d) Gegebenenfalls Separata ausgewählter Publikationen

Im Namen des Vorstandes Der Präsident:

Prof. W. 1'on Philipshorn Organisch-chemisches Institut Universität Zürich-Irchel Winterthurerstrasse 190 CH-8057 Zürich
Les propositions et candidatures présentées pour l'attribution de ce prix pour l'année 1992, avec les documents sous-mentionnés, doivent être adressées au président avant le 31 mai 1991.

a) Proposition motivée

b) Curriculum vitae

c) Liste de publications

d) Cas échéant tirés à part des publications selectionées

Au nom du Comité

Le Président:

Prof. W. I'on Philipshom

Organisch-chemisches Institut

Universität Zürich-Irchel

Winterthurerstrasse 190

$\mathrm{CH}-8057$ Zürich

\section{Schweizerischer Chemiker-Verband \\ Association Suisse des Chimistes Swiss Association of Chemists}

\section{Voranzeige}

Die diesjährige Frühjahrsversammlung und die Generalversammlung 1991 finden am 18. nachmittags und am 19. April 1991 in Agno/Lugano, Hotel la Perla, statt.

Die Frühjahrsversammlung wird der Tessiner Pharmaindustrie gewidmet sein

(Vorträge und Besichtigungen).

\section{Chemische Gesellschaft Fribourg}

\section{März 1991 \\ Prof. Dr. IA Robinson}

17.15 h, Universität Zürich

'Chemical and Biochemical Studies of Polyether Antibiotic Biosynthesis'
Die GV 1991 wird sich hauptsächlich mit der Neugründung einer neuen schweizerischen chemischen Gesellschaft befassen.

Die definitiven Einladungen werden anfangs März 1991 verschickt.

Bitte diese Termine vormerken

Der Vorstand

Die Vorträge finden statt jeweils dienstags, $17.15 \mathrm{~h} \mathrm{im} \mathrm{grossen} \mathrm{Hörsaal}$ der Chemischen Institute der Universität Fribourg (Pérolles). 
nierte Mitglieder geniessen mit einem entsprechenden Vermerks bei der Einzahlung die gleiche Vergünstigung wie Studenten.

4. Wahlen für Amtsperiode $1991-$ 92. Für weitere zwei Jahre werden durch Akklamation bestätigt: Dr. D. Hauser (Sandoz Pharma AG, Basel) als Beisitzer, Prof. J. Wirz (Univ. Basel) als Rechnungsrevisor.

Damit setzl sich der Vorstand für 1991-92 wie folgt zusammen:

Präsident:

W. von Philipsborn, Zürich

Vizepräsident:

A.E. Merbach, Lausanne

Schatzmeister:

J. Kalvoda, Basel

Altpräsidenten:

T. Gäumann, Lausanne

G. Ohloff, Genf

A. Eschenmoser, Zürich

Beisitzer:

D. Hauser, Basel

D. Bellus, Basel

K. Müller, Basel

D. Seebach, Zürich

Vertreter des Redaktionskomitees Helvetica Chimica Acta:

E. Heilbronner, Herrliberg

L.M. Venanzi, Zürich

H.-J. Hansen, Zürich

Ch. Tamm, Basel

Redaktor Helv. Chim. Acta

M.V. Kısakürek, Basel

Rechnungsrevisoren:

J. Wirz, Basel

P. Zeller, Basel

Sekretïr:

E. Zass, Zürich

Das Redaktionskomitee Helvetica Chimica Acta hat folgende Mitglieder:

Präsident:

E. Heilbronner, Herrliberg

Vizepräsidenten:

L.M. Venanzi, Zürich

H.-J. Hansen, Zürich

Ch. Tamm, Basel

Beisitzer:

H.-B. Buirgi, Bern

H. Heimgartner, Zürich

M. Hesse, Zürich

A. Kaiser, Basel

A.E. Merbach, Lausanne

K. Müller, Basel

W. Oppolzer, Genf

D. Seebach, Zürich

A. Vasella, Zürich

J. Wirz, Basel

Redaktor:

M.V. Kısakürek, Basel

\section{Werner-Preis}

Der Vorstand teilt den Mitgliedern der Schweizerischen Chemischen Gesellschaft mit, dass dieser Preis an der Frühjahrsversammlung 1992 nach den Bestimmungen der
5. Der Präsident informiert über den Fortgang der Kooperation von SCG und SChV (gemeinsam veranstaltete Tagungen, gemeinsame technische Redaktion von Helvetica Chimica Acta und Chimia) und über den Stand der Fusionsvorbereitungen beiderGesellschaften. Ein Entwurf für Struktur und Statuten der neuen Gesellschaft und ihrer Sektionen sowie ein 12-PunkteProgramm für neue Leistungen liegen vor; die Mitglieder werden in einem gemeinsamen Kommunique im Heft 12/90 der Chimia informiert.

6. Varia: Keine Wortmeldung Schluss der Sitzung: 8.55 Uhr

\section{B. Wissenschaftlicher Teil}

Das Programm enthielt den Vortrag des Werner-Preisträgers 1990 Dr. H. Frei (Univ. of California, Berkeley, USA) 'Chemistry with red and near infrared light', das Symposium 'Recent Developments in Organometallic Chemistry and Homogeneous Catalysis' mit Vorträgen von H. Berke (Univ. Zürich) 'The tuning of organometallic insertion reactions', $G$. Süss-Fink (Univ. de Neuchâtel) 'Anionic ruthenium clusters as hydroformylation catalysts Recent and previous results', $W . I$. Evans (Univ. of California, Irvine/ USA) 'Chemistry within a dynamic tetracyclopentadienyl cavity? Some recent results in organolanthanide chemistry', T. Hayashi (Hokkaido Univ., Sapporo/Japan)'Asymmetric synthesis catalyzed by chiral ferrocenylphosphine - transition metal complexes', und das Seminar 'Analytische Chemie' des erstmals als Gast an der Herbstversammlung teilnehmenden Comité Suisse de Chimie Analytique mit 10 Vorträgen und 34 Postem. Die Sektion Medizinische Chemie organisierte 13 Vorträge und Kurzmitteilungen, weitere Kurzmitteilungen wurden in Organischer Chemie (insgesamt 36 in zwei Parallelsessionen), Physikalischer Chemie (11) und im $\mathrm{Mi}$ nisymposium 'Computational Chemistry' (7) präsentiert. Die Anorganische Chemie und Koordinationschemie waren ausser dem erwähnten Minisymposium noch mit 47 Postern vertreten.

Der Präsident:

Prof. W. von Philipsborn

Der Sekretär:

Dr. E. Zass

Artikel 23-26 der Statuten verliehen werden kann:

«Der Preis mit Medaille kann in jährlichem Turnus an schweizerische oder in der Schweiz tätige, aus- ländische Nachwuchswissenschafter für ausgezeichnete Forschungsarbeiten auf dem Gebiete der Chemie verliehen werden. Pro Jahr werden in der Regel höchstens zwei Werner-Preise erteilt. Die Auswahl der Preisträger hat sich nicht auf Kandidaten zu beschränken, die an einer Hochschule tätig sind. Ausnahmsweise kann der Preis auch an ältere Forscher verliehen werden.»

. Vorschläge und Bewerbungen sind mit den nachstehend aufgeführten Belegen dem Präsidenten der SCG bis zum 31. Mai 1991 einzureichen.

\section{Prix Werner}

Le Comité informe les membres de la Société Suisse de Chimie que ce prix peut être attribué à l'assemblée de printemps 1992 conformément aux conditions définies dans les articles 23-26 des statuts:

«Le prix, qui est doté d'une médaille, peut être attribué annuellement à des jeunes chercheurs suisses, ou étrangers travaillant en Suisse, pour des travaux de recherche de haut niveau dans le domaine de la chimie. Dans la règle, pas plus de deux prix Werner ne sont décernés par année. Le choix des candidats à ce prix ne doit pas se limiter à ceux qui travaillent dans une université Exceptionellement le prix peut être attribué à un chercheur âgé.»

a) Antrag mit Begründung

b) Curriculum vitae

c) Publikationsliste

d) Gegebenenfalls Separata ausgewählter Publikationen

Im Namen des Vorstandes Der Präsident:

Prof. W. 1'on Philipshorn Organisch-chemisches Institut Universität Zürich-Irchel Winterthurerstrasse 190 CH-8057 Zürich
Les propositions et candidatures présentées pour l'attribution de ce prix pour l'année 1992, avec les documents sous-mentionnés, doivent être adressées au président avant le 31 mai 1991.

a) Proposition motivée

b) Curriculum vitae

c) Liste de publications

d) Cas échéant tirés à part des publications selectionées

Au nom du Comité

Le Président:

Prof. W. I'on Philipshom

Organisch-chemisches Institut

Universität Zürich-Irchel

Winterthurerstrasse 190

$\mathrm{CH}-8057$ Zürich

\section{Schweizerischer Chemiker-Verband \\ Association Suisse des Chimistes Swiss Association of Chemists}

\section{Voranzeige}

Die diesjährige Frühjahrsversammlung und die Generalversammlung 1991 finden am 18. nachmittags und am 19. April 1991 in Agno/Lugano, Hotel la Perla, statt.

Die Frühjahrsversammlung wird der Tessiner Pharmaindustrie gewidmet sein

(Vorträge und Besichtigungen).

\section{Chemische Gesellschaft Fribourg}

\section{März 1991 \\ Prof. Dr. IA Robinson}

17.15 h, Universität Zürich

'Chemical and Biochemical Studies of Polyether Antibiotic Biosynthesis'
Die GV 1991 wird sich hauptsächlich mit der Neugründung einer neuen schweizerischen chemischen Gesellschaft befassen.

Die definitiven Einladungen werden anfangs März 1991 verschickt.

Bitte diese Termine vormerken

Der Vorstand

Die Vorträge finden statt jeweils dienstags, $17.15 \mathrm{~h} \mathrm{im} \mathrm{grossen} \mathrm{Hörsaal}$ der Chemischen Institute der Universität Fribourg (Pérolles). 
nierte Mitglieder geniessen mit einem entsprechenden Vermerks bei der Einzahlung die gleiche Vergünstigung wie Studenten.

4. Wahlen für Amtsperiode $1991-$ 92. Für weitere zwei Jahre werden durch Akklamation bestätigt: Dr. D. Hauser (Sandoz Pharma AG, Basel) als Beisitzer, Prof. J. Wirz (Univ. Basel) als Rechnungsrevisor.

Damit setzl sich der Vorstand für 1991-92 wie folgt zusammen:

Präsident:

W. von Philipsborn, Zürich

Vizepräsident:

A.E. Merbach, Lausanne

Schatzmeister:

J. Kalvoda, Basel

Altpräsidenten:

T. Gäumann, Lausanne

G. Ohloff, Genf

A. Eschenmoser, Zürich

Beisitzer:

D. Hauser, Basel

D. Bellus, Basel

K. Müller, Basel

D. Seebach, Zürich

Vertreter des Redaktionskomitees Helvetica Chimica Acta:

E. Heilbronner, Herrliberg

L.M. Venanzi, Zürich

H.-J. Hansen, Zürich

Ch. Tamm, Basel

Redaktor Helv. Chim. Acta

M.V. Kısakürek, Basel

Rechnungsrevisoren:

J. Wirz, Basel

P. Zeller, Basel

Sekretïr:

E. Zass, Zürich

Das Redaktionskomitee Helvetica Chimica Acta hat folgende Mitglieder:

Präsident:

E. Heilbronner, Herrliberg

Vizepräsidenten:

L.M. Venanzi, Zürich

H.-J. Hansen, Zürich

Ch. Tamm, Basel

Beisitzer:

H.-B. Buirgi, Bern

H. Heimgartner, Zürich

M. Hesse, Zürich

A. Kaiser, Basel

A.E. Merbach, Lausanne

K. Müller, Basel

W. Oppolzer, Genf

D. Seebach, Zürich

A. Vasella, Zürich

J. Wirz, Basel

Redaktor:

M.V. Kısakürek, Basel

\section{Werner-Preis}

Der Vorstand teilt den Mitgliedern der Schweizerischen Chemischen Gesellschaft mit, dass dieser Preis an der Frühjahrsversammlung 1992 nach den Bestimmungen der
5. Der Präsident informiert über den Fortgang der Kooperation von SCG und SChV (gemeinsam veranstaltete Tagungen, gemeinsame technische Redaktion von Helvetica Chimica Acta und Chimia) und über den Stand der Fusionsvorbereitungen beiderGesellschaften. Ein Entwurf für Struktur und Statuten der neuen Gesellschaft und ihrer Sektionen sowie ein 12-PunkteProgramm für neue Leistungen liegen vor; die Mitglieder werden in einem gemeinsamen Kommunique im Heft 12/90 der Chimia informiert.

6. Varia: Keine Wortmeldung Schluss der Sitzung: 8.55 Uhr

\section{B. Wissenschaftlicher Teil}

Das Programm enthielt den Vortrag des Werner-Preisträgers 1990 Dr. H. Frei (Univ. of California, Berkeley, USA) 'Chemistry with red and near infrared light', das Symposium 'Recent Developments in Organometallic Chemistry and Homogeneous Catalysis' mit Vorträgen von H. Berke (Univ. Zürich) 'The tuning of organometallic insertion reactions', $G$. Süss-Fink (Univ. de Neuchâtel) 'Anionic ruthenium clusters as hydroformylation catalysts Recent and previous results', $W . I$. Evans (Univ. of California, Irvine/ USA) 'Chemistry within a dynamic tetracyclopentadienyl cavity? Some recent results in organolanthanide chemistry', T. Hayashi (Hokkaido Univ., Sapporo/Japan)'Asymmetric synthesis catalyzed by chiral ferrocenylphosphine - transition metal complexes', und das Seminar 'Analytische Chemie' des erstmals als Gast an der Herbstversammlung teilnehmenden Comité Suisse de Chimie Analytique mit 10 Vorträgen und 34 Postem. Die Sektion Medizinische Chemie organisierte 13 Vorträge und Kurzmitteilungen, weitere Kurzmitteilungen wurden in Organischer Chemie (insgesamt 36 in zwei Parallelsessionen), Physikalischer Chemie (11) und im $\mathrm{Mi}$ nisymposium 'Computational Chemistry' (7) präsentiert. Die Anorganische Chemie und Koordinationschemie waren ausser dem erwähnten Minisymposium noch mit 47 Postern vertreten.

Der Präsident:

Prof. W. von Philipsborn

Der Sekretär:

Dr. E. Zass

Artikel 23-26 der Statuten verliehen werden kann:

«Der Preis mit Medaille kann in jährlichem Turnus an schweizerische oder in der Schweiz tätige, aus- ländische Nachwuchswissenschafter für ausgezeichnete Forschungsarbeiten auf dem Gebiete der Chemie verliehen werden. Pro Jahr werden in der Regel höchstens zwei Werner-Preise erteilt. Die Auswahl der Preisträger hat sich nicht auf Kandidaten zu beschränken, die an einer Hochschule tätig sind. Ausnahmsweise kann der Preis auch an ältere Forscher verliehen werden.»

. Vorschläge und Bewerbungen sind mit den nachstehend aufgeführten Belegen dem Präsidenten der SCG bis zum 31. Mai 1991 einzureichen.

\section{Prix Werner}

Le Comité informe les membres de la Société Suisse de Chimie que ce prix peut être attribué à l'assemblée de printemps 1992 conformément aux conditions définies dans les articles 23-26 des statuts:

«Le prix, qui est doté d'une médaille, peut être attribué annuellement à des jeunes chercheurs suisses, ou étrangers travaillant en Suisse, pour des travaux de recherche de haut niveau dans le domaine de la chimie. Dans la règle, pas plus de deux prix Werner ne sont décernés par année. Le choix des candidats à ce prix ne doit pas se limiter à ceux qui travaillent dans une université Exceptionellement le prix peut être attribué à un chercheur âgé.»

a) Antrag mit Begründung

b) Curriculum vitae

c) Publikationsliste

d) Gegebenenfalls Separata ausgewählter Publikationen

Im Namen des Vorstandes Der Präsident:

Prof. W. 1'on Philipshorn Organisch-chemisches Institut Universität Zürich-Irchel Winterthurerstrasse 190 CH-8057 Zürich
Les propositions et candidatures présentées pour l'attribution de ce prix pour l'année 1992, avec les documents sous-mentionnés, doivent être adressées au président avant le 31 mai 1991.

a) Proposition motivée

b) Curriculum vitae

c) Liste de publications

d) Cas échéant tirés à part des publications selectionées

Au nom du Comité

Le Président:

Prof. W. I'on Philipshom

Organisch-chemisches Institut

Universität Zürich-Irchel

Winterthurerstrasse 190

$\mathrm{CH}-8057$ Zürich

\section{Schweizerischer Chemiker-Verband \\ Association Suisse des Chimistes Swiss Association of Chemists}

\section{Voranzeige}

Die diesjährige Frühjahrsversammlung und die Generalversammlung 1991 finden am 18. nachmittags und am 19. April 1991 in Agno/Lugano, Hotel la Perla, statt.

Die Frühjahrsversammlung wird der Tessiner Pharmaindustrie gewidmet sein

(Vorträge und Besichtigungen).

\section{Chemische Gesellschaft Fribourg}

\section{März 1991 \\ Prof. Dr. IA Robinson}

17.15 h, Universität Zürich

'Chemical and Biochemical Studies of Polyether Antibiotic Biosynthesis'
Die GV 1991 wird sich hauptsächlich mit der Neugründung einer neuen schweizerischen chemischen Gesellschaft befassen.

Die definitiven Einladungen werden anfangs März 1991 verschickt.

Bitte diese Termine vormerken

Der Vorstand

Die Vorträge finden statt jeweils dienstags, $17.15 \mathrm{~h} \mathrm{im} \mathrm{grossen} \mathrm{Hörsaal}$ der Chemischen Institute der Universität Fribourg (Pérolles). 


\section{Branche Chemie setzt sich Leitplanken zur Gentechnik}

Die Schweizerische Gesellschaft für Chemische Industrie (SGCI) hat soeben die «Leitlinen zur Gentechnik" publiziert, die sich die auf diesem Gebiet tätigen Chemiefirmen in der Schweiz gegeben haben. Die Gentechnik zählt zu den Schlüsseltechnologien der Zukunft, weil sie neue Möglichkeiten eröffnet für die Erforschung und Therapie von bisher unbehandelbaren Krankheiten, für die Erzeugung von Nahrungsmitteln, für die Verbesserung des Pflanzenschutzes, sowie für die Entwicklung von energiesparenden und umweltschonenden Produktionsverfahren.

Die chemische und pharmazeutische Industrie der Schweiz will sich deshalb die Methoden der Gentechnik zunutze machen. Sie hat für den verantwortungsvollen Umgang mit dieser Technik die nachstehenden Leitlinien erarbeitet, die sie befolgen will:

\section{SGCl-Leitlinien zur Gentechnik}

Die Schweizerische Gesellschaft für Chemische Industrie (SGCI) betrachtet die Gentechnik als eine Schlüsseltechnologie der Zukunft.

Die Gentechnik ist von grossem Nutzen und trägt dazu bei,

- Krankheiten und ihre Ursachen zu erforschen und mit diesen Erkenntnissen präzisere diagnostische Methoden, wirksamere Arzneimittel und neue Wirkstoffe für die Gesundheit von Mensch und Tier zu entwickeln und herzustellen,

- die Nahrungsmittelerzeugung zu verbessern, landwirtschaftliche Methoden weiterzuentwickeln und den Pflanzenschutz gezielter und effizienter zu gestalten,

- Energie und Ressourcen zu sparen und umweltfreundliche Produktionsverfahren durch den Einsatz biotechnischer Prozesse zu entwickeln.

Die SGCI empfiehlt ihren Mitgliedern, Grundsätze der firmeneigenen Politik im Bereich der Gentechnik zu erstellen und regelmässig zu überprüfen. Zusätzlich sind Verfahren zu deren Implementierung, Aktualisierung und Kontrolle auszuarbeiten.

Verantwortung

Die Unternehmen der SGCI fördern und pflegen das Verständnis für ein verantwortliches Handeln bei den in diesem Bereich tätigen Mitarbeiterinnen und Mitarbeiter aller Stufen durch Aus- und Weiterbildung sowie durch geeignete Massnahmen im Bereich des Arbeitsschutzes.

\section{Sicherheit}

Beim Einsatz von genetischen Methoden sowie bei der Beurteilung der Risiken haben die Sicherheit der Mitarbeiterinnen und Mitarbeiter, von Mensch und Tier allgemein, sowie der Schutz der Umwelt Priorität.

\section{Ethische Grenzen}

Die Unternehmen der SGCI lassen sich von ethischen Wertvorstellungen leiten. Sie befassen sich nicht mit genetischen Veränderungen des Erbgutes in menschlichen Keimbahnzellen und in menschlichen Embryonen.

\section{Internationale Standards}

Die Unternehmen der SGCI wenden in der Beurteilung der gentechnischen Forschung und ihren Anwendungen die international anerkannten Empfehlungen der OECD und die Richtlinien der amerikanischen National Institutes of Health (NIH) an. Solange keine detaillierte gesetzliche Regelung besteht, registrieren sie gentechnische Forschungsvorhaben bei der «Interdisziplinären schweizerischen Kommission für biologische Sicherheit (SKBS)».

\section{Gesetzgebung}

Die Unternehmen der SGCI befürworten eine Oberaufsicht des Bundes über die «Interdisziplinäre schweizerische Kommission für biologische Sicherheit»"sowie die Anpassung der bestehenden Gesetzgebung auf Bundesebene zur Verhinderung von Missbräuchen und zum Schutz der Persönlichkeit sowie allgemein von Mensch und Umwelt.

\section{Information}

Eine breite und offene Information der Öffentlichkeit über die Chancen und die möglichen Probleme der Gentechnik ist notwendig. Die Unternehmen der SGCI bemühen sich um grösstmögliche Transparenz über ihre konkreten Tätigkeiten und Absichten im Bereich der Gentechnik. Sie unterstützen soweit als möglich die Bemühungen der Wissenschaftlerinnen und Wissenschaftler, allgemein verständlich und sachlich über die neuen Entwicklungen in diesem Forschungsbereich sowie über die Gesamtzusammenhänge zu informieren.

\section{Personalia}

\section{Geburtstage}

Karl G. Scheibli,

Dr. sc. techn., Bottmingen, Mitglied des SChV, feiert am 2.3.91 seinen 65 . Geburtstag.

\section{Albert Strüby,}

Chemiker HTL, Spiez, Mitglied des SChV, feiert am 3.3.91 seinen 65. Geburtstag.

Werner Weber,

Prof. Dr. sc. nat, St. Gallen, Mitglied des SChV, feiert an 6.3.91 seinen 80 . Geburtstag.

Hans Süss,

Chemiker HTL, Untersiggenthal, Mitglied des SChV, feiert am 10.3.91 seinen 70 . Geburtstag.

\section{Neue Mitglieder}

Lucas Auer, Bellevuestrasse 131, 3028 Spiegel

Urs Glättli, Rotackerstrasse 29, 8304 Wallisellen

Antonio Pessina, Dr. sc. nat., 6853 Ligornetto

\section{SYNOPOSIS}

\section{Nomenclature of kinetic}

methods of analysis

The report lists, in alphabetical order, names and definitions of 41 terms, most widely used in kinetic methods of analysis. These include kinetic, differential-kinetic, catalytic and enzymatic terms. They have
Ernst Schumacher-Christ,

Prof. Dr., Bremgarten, Mitglied des SChV, feiert am 12.3.91 seinen 65. Geburtstag

Werner Zimmermann, Chemiker HTL, Riehen, Mitglied des SChV, feiert am 17.3.91 seinen 65. Geburtstag.

Andreas Gïumann.

Dr. phil. II, Feldmeilen, Mitglied des SChV, feiert am 23.3.91 seinen 70. Geburtstag.

Alex Caspi

Chemiker HTL, Basel, Mitglied des SChV, feiert am 29.3.91 seinen 65. Geburtstag.

\section{SATW Schweizerische Akademie der Technischen Wissenschaften}

Vorschau auf Veranstaltungen in der HEUREKA, dernationalen Forschungsausstellung zum 700 jährigen Bestehen derEidgenossenschaft, Allmend Brunau, Zürich-Enge

Kolloquium der 4 Akademien: "Freiheit und Grenzen der Forschung"

Die Konferenz der Schweizerischen Wissenschaftlichen Akademien wird am Freitag, den 24. Mai 1991 im Rahmen der Nationalen Forschungsausstellung «Heureka» in Zürich ein Kolloquium unter dem Generaltitel «Freiheit und Grenzen der Forschung» durchführen.

Tagung der SATW:

Samstag 22. Juni 1990

Nobelpreisträger stellen sich vor been harmonized with other previously published IUPAC documents.

Comments on the document are welcome and should be sent by 31 st October 1991 to:

G. Svehla, Department of Chemistry, University College Cork, Cork, Ireland.
Die SATW möchte mit dieser Tagung einer breiten Öffentlichkeit die Technik, ihre Ziele und Leistungen näher bringen und den Dialog mit der Allgemeinheit suchen und festigen. Die 4 Nobelpreistriger Prof.WernerAsber (Medizin 1978), Prof. Robert Huber (Chemie, 1988), Prof.K.AlexMïller, (Physik, 1987), Dr. Heinrich Rohrer (Physik 1986) haben als Referenten zugesagt. Als Moderatoren werden wirken Direktor $F$. Sutter (ASCOM Holding AG Bern) und Prof. Heimrich Ur. sprung (Direktor der Gruppe für Wissenschaft und Forschung im Eidg. Departement des Innern).

Als Panel-Mitglieder haben zugesagt für die Vorträge «Biologic, Medizin und Chemie» Dr. Hans Jucker, Delegierter des Verwal- 


\section{Branche Chemie setzt sich Leitplanken zur Gentechnik}

Die Schweizerische Gesellschaft für Chemische Industrie (SGCI) hat soeben die «Leitlinen zur Gentechnik" publiziert, die sich die auf diesem Gebiet tätigen Chemiefirmen in der Schweiz gegeben haben. Die Gentechnik zählt zu den Schlüsseltechnologien der Zukunft, weil sie neue Möglichkeiten eröffnet für die Erforschung und Therapie von bisher unbehandelbaren Krankheiten, für die Erzeugung von Nahrungsmitteln, für die Verbesserung des Pflanzenschutzes, sowie für die Entwicklung von energiesparenden und umweltschonenden Produktionsverfahren.

Die chemische und pharmazeutische Industrie der Schweiz will sich deshalb die Methoden der Gentechnik zunutze machen. Sie hat für den verantwortungsvollen Umgang mit dieser Technik die nachstehenden Leitlinien erarbeitet, die sie befolgen will:

\section{SGCl-Leitlinien zur Gentechnik}

Die Schweizerische Gesellschaft für Chemische Industrie (SGCI) betrachtet die Gentechnik als eine Schlüsseltechnologie der Zukunft.

Die Gentechnik ist von grossem Nutzen und trägt dazu bei,

- Krankheiten und ihre Ursachen zu erforschen und mit diesen Erkenntnissen präzisere diagnostische Methoden, wirksamere Arzneimittel und neue Wirkstoffe für die Gesundheit von Mensch und Tier zu entwickeln und herzustellen,

- die Nahrungsmittelerzeugung zu verbessern, landwirtschaftliche Methoden weiterzuentwickeln und den Pflanzenschutz gezielter und effizienter zu gestalten,

- Energie und Ressourcen zu sparen und umweltfreundliche Produktionsverfahren durch den Einsatz biotechnischer Prozesse zu entwickeln.

Die SGCI empfiehlt ihren Mitgliedern, Grundsätze der firmeneigenen Politik im Bereich der Gentechnik zu erstellen und regelmässig zu überprüfen. Zusätzlich sind Verfahren zu deren Implementierung, Aktualisierung und Kontrolle auszuarbeiten.

Verantwortung

Die Unternehmen der SGCI fördern und pflegen das Verständnis für ein verantwortliches Handeln bei den in diesem Bereich tätigen Mitarbeiterinnen und Mitarbeiter aller Stufen durch Aus- und Weiterbildung sowie durch geeignete Massnahmen im Bereich des Arbeitsschutzes.

\section{Sicherheit}

Beim Einsatz von genetischen Methoden sowie bei der Beurteilung der Risiken haben die Sicherheit der Mitarbeiterinnen und Mitarbeiter, von Mensch und Tier allgemein, sowie der Schutz der Umwelt Priorität.

\section{Ethische Grenzen}

Die Unternehmen der SGCI lassen sich von ethischen Wertvorstellungen leiten. Sie befassen sich nicht mit genetischen Veränderungen des Erbgutes in menschlichen Keimbahnzellen und in menschlichen Embryonen.

\section{Internationale Standards}

Die Unternehmen der SGCI wenden in der Beurteilung der gentechnischen Forschung und ihren Anwendungen die international anerkannten Empfehlungen der OECD und die Richtlinien der amerikanischen National Institutes of Health (NIH) an. Solange keine detaillierte gesetzliche Regelung besteht, registrieren sie gentechnische Forschungsvorhaben bei der «Interdisziplinären schweizerischen Kommission für biologische Sicherheit (SKBS)».

\section{Gesetzgebung}

Die Unternehmen der SGCI befürworten eine Oberaufsicht des Bundes über die «Interdisziplinäre schweizerische Kommission für biologische Sicherheit»"sowie die Anpassung der bestehenden Gesetzgebung auf Bundesebene zur Verhinderung von Missbräuchen und zum Schutz der Persönlichkeit sowie allgemein von Mensch und Umwelt.

\section{Information}

Eine breite und offene Information der Öffentlichkeit über die Chancen und die möglichen Probleme der Gentechnik ist notwendig. Die Unternehmen der SGCI bemühen sich um grösstmögliche Transparenz über ihre konkreten Tätigkeiten und Absichten im Bereich der Gentechnik. Sie unterstützen soweit als möglich die Bemühungen der Wissenschaftlerinnen und Wissenschaftler, allgemein verständlich und sachlich über die neuen Entwicklungen in diesem Forschungsbereich sowie über die Gesamtzusammenhänge zu informieren.

\section{Personalia}

\section{Geburtstage}

Karl G. Scheibli,

Dr. sc. techn., Bottmingen, Mitglied des SChV, feiert am 2.3.91 seinen 65 . Geburtstag.

\section{Albert Strüby,}

Chemiker HTL, Spiez, Mitglied des SChV, feiert am 3.3.91 seinen 65. Geburtstag.

Werner Weber,

Prof. Dr. sc. nat, St. Gallen, Mitglied des SChV, feiert an 6.3.91 seinen 80 . Geburtstag.

Hans Süss,

Chemiker HTL, Untersiggenthal, Mitglied des SChV, feiert am 10.3.91 seinen 70 . Geburtstag.

\section{Neue Mitglieder}

Lucas Auer, Bellevuestrasse 131, 3028 Spiegel

Urs Glättli, Rotackerstrasse 29, 8304 Wallisellen

Antonio Pessina, Dr. sc. nat., 6853 Ligornetto

\section{SYNOPOSIS}

\section{Nomenclature of kinetic}

methods of analysis

The report lists, in alphabetical order, names and definitions of 41 terms, most widely used in kinetic methods of analysis. These include kinetic, differential-kinetic, catalytic and enzymatic terms. They have
Ernst Schumacher-Christ,

Prof. Dr., Bremgarten, Mitglied des SChV, feiert am 12.3.91 seinen 65. Geburtstag

Werner Zimmermann, Chemiker HTL, Riehen, Mitglied des SChV, feiert am 17.3.91 seinen 65. Geburtstag.

Andreas Gïumann.

Dr. phil. II, Feldmeilen, Mitglied des SChV, feiert am 23.3.91 seinen 70. Geburtstag.

Alex Caspi

Chemiker HTL, Basel, Mitglied des SChV, feiert am 29.3.91 seinen 65. Geburtstag.

\section{SATW Schweizerische Akademie der Technischen Wissenschaften}

Vorschau auf Veranstaltungen in der HEUREKA, dernationalen Forschungsausstellung zum 700 jährigen Bestehen derEidgenossenschaft, Allmend Brunau, Zürich-Enge

Kolloquium der 4 Akademien: "Freiheit und Grenzen der Forschung"

Die Konferenz der Schweizerischen Wissenschaftlichen Akademien wird am Freitag, den 24. Mai 1991 im Rahmen der Nationalen Forschungsausstellung «Heureka» in Zürich ein Kolloquium unter dem Generaltitel «Freiheit und Grenzen der Forschung» durchführen.

Tagung der SATW:

Samstag 22. Juni 1990

Nobelpreisträger stellen sich vor been harmonized with other previously published IUPAC documents.

Comments on the document are welcome and should be sent by 31 st October 1991 to:

G. Svehla, Department of Chemistry, University College Cork, Cork, Ireland.
Die SATW möchte mit dieser Tagung einer breiten Öffentlichkeit die Technik, ihre Ziele und Leistungen näher bringen und den Dialog mit der Allgemeinheit suchen und festigen. Die 4 Nobelpreistriger Prof.WernerAsber (Medizin 1978), Prof. Robert Huber (Chemie, 1988), Prof.K.AlexMïller, (Physik, 1987), Dr. Heinrich Rohrer (Physik 1986) haben als Referenten zugesagt. Als Moderatoren werden wirken Direktor $F$. Sutter (ASCOM Holding AG Bern) und Prof. Heimrich Ur. sprung (Direktor der Gruppe für Wissenschaft und Forschung im Eidg. Departement des Innern).

Als Panel-Mitglieder haben zugesagt für die Vorträge «Biologic, Medizin und Chemie» Dr. Hans Jucker, Delegierter des Verwal- 


\section{Branche Chemie setzt sich Leitplanken zur Gentechnik}

Die Schweizerische Gesellschaft für Chemische Industrie (SGCI) hat soeben die «Leitlinen zur Gentechnik" publiziert, die sich die auf diesem Gebiet tätigen Chemiefirmen in der Schweiz gegeben haben. Die Gentechnik zählt zu den Schlüsseltechnologien der Zukunft, weil sie neue Möglichkeiten eröffnet für die Erforschung und Therapie von bisher unbehandelbaren Krankheiten, für die Erzeugung von Nahrungsmitteln, für die Verbesserung des Pflanzenschutzes, sowie für die Entwicklung von energiesparenden und umweltschonenden Produktionsverfahren.

Die chemische und pharmazeutische Industrie der Schweiz will sich deshalb die Methoden der Gentechnik zunutze machen. Sie hat für den verantwortungsvollen Umgang mit dieser Technik die nachstehenden Leitlinien erarbeitet, die sie befolgen will:

\section{SGCl-Leitlinien zur Gentechnik}

Die Schweizerische Gesellschaft für Chemische Industrie (SGCI) betrachtet die Gentechnik als eine Schlüsseltechnologie der Zukunft.

Die Gentechnik ist von grossem Nutzen und trägt dazu bei,

- Krankheiten und ihre Ursachen zu erforschen und mit diesen Erkenntnissen präzisere diagnostische Methoden, wirksamere Arzneimittel und neue Wirkstoffe für die Gesundheit von Mensch und Tier zu entwickeln und herzustellen,

- die Nahrungsmittelerzeugung zu verbessern, landwirtschaftliche Methoden weiterzuentwickeln und den Pflanzenschutz gezielter und effizienter zu gestalten,

- Energie und Ressourcen zu sparen und umweltfreundliche Produktionsverfahren durch den Einsatz biotechnischer Prozesse zu entwickeln.

Die SGCI empfiehlt ihren Mitgliedern, Grundsätze der firmeneigenen Politik im Bereich der Gentechnik zu erstellen und regelmässig zu überprüfen. Zusätzlich sind Verfahren zu deren Implementierung, Aktualisierung und Kontrolle auszuarbeiten.

Verantwortung

Die Unternehmen der SGCI fördern und pflegen das Verständnis für ein verantwortliches Handeln bei den in diesem Bereich tätigen Mitarbeiterinnen und Mitarbeiter aller Stufen durch Aus- und Weiterbildung sowie durch geeignete Massnahmen im Bereich des Arbeitsschutzes.

\section{Sicherheit}

Beim Einsatz von genetischen Methoden sowie bei der Beurteilung der Risiken haben die Sicherheit der Mitarbeiterinnen und Mitarbeiter, von Mensch und Tier allgemein, sowie der Schutz der Umwelt Priorität.

\section{Ethische Grenzen}

Die Unternehmen der SGCI lassen sich von ethischen Wertvorstellungen leiten. Sie befassen sich nicht mit genetischen Veränderungen des Erbgutes in menschlichen Keimbahnzellen und in menschlichen Embryonen.

\section{Internationale Standards}

Die Unternehmen der SGCI wenden in der Beurteilung der gentechnischen Forschung und ihren Anwendungen die international anerkannten Empfehlungen der OECD und die Richtlinien der amerikanischen National Institutes of Health (NIH) an. Solange keine detaillierte gesetzliche Regelung besteht, registrieren sie gentechnische Forschungsvorhaben bei der «Interdisziplinären schweizerischen Kommission für biologische Sicherheit (SKBS)».

\section{Gesetzgebung}

Die Unternehmen der SGCI befürworten eine Oberaufsicht des Bundes über die «Interdisziplinäre schweizerische Kommission für biologische Sicherheit»"sowie die Anpassung der bestehenden Gesetzgebung auf Bundesebene zur Verhinderung von Missbräuchen und zum Schutz der Persönlichkeit sowie allgemein von Mensch und Umwelt.

\section{Information}

Eine breite und offene Information der Öffentlichkeit über die Chancen und die möglichen Probleme der Gentechnik ist notwendig. Die Unternehmen der SGCI bemühen sich um grösstmögliche Transparenz über ihre konkreten Tätigkeiten und Absichten im Bereich der Gentechnik. Sie unterstützen soweit als möglich die Bemühungen der Wissenschaftlerinnen und Wissenschaftler, allgemein verständlich und sachlich über die neuen Entwicklungen in diesem Forschungsbereich sowie über die Gesamtzusammenhänge zu informieren.

\section{Personalia}

\section{Geburtstage}

Karl G. Scheibli,

Dr. sc. techn., Bottmingen, Mitglied des SChV, feiert am 2.3.91 seinen 65 . Geburtstag.

\section{Albert Strüby,}

Chemiker HTL, Spiez, Mitglied des SChV, feiert am 3.3.91 seinen 65. Geburtstag.

Werner Weber,

Prof. Dr. sc. nat, St. Gallen, Mitglied des SChV, feiert an 6.3.91 seinen 80 . Geburtstag.

Hans Süss,

Chemiker HTL, Untersiggenthal, Mitglied des SChV, feiert am 10.3.91 seinen 70 . Geburtstag.

\section{Neue Mitglieder}

Lucas Auer, Bellevuestrasse 131, 3028 Spiegel

Urs Glättli, Rotackerstrasse 29, 8304 Wallisellen

Antonio Pessina, Dr. sc. nat., 6853 Ligornetto

\section{SYNOPOSIS}

\section{Nomenclature of kinetic}

methods of analysis

The report lists, in alphabetical order, names and definitions of 41 terms, most widely used in kinetic methods of analysis. These include kinetic, differential-kinetic, catalytic and enzymatic terms. They have
Ernst Schumacher-Christ,

Prof. Dr., Bremgarten, Mitglied des SChV, feiert am 12.3.91 seinen 65. Geburtstag

Werner Zimmermann, Chemiker HTL, Riehen, Mitglied des SChV, feiert am 17.3.91 seinen 65. Geburtstag.

Andreas Gïumann.

Dr. phil. II, Feldmeilen, Mitglied des SChV, feiert am 23.3.91 seinen 70. Geburtstag.

Alex Caspi

Chemiker HTL, Basel, Mitglied des SChV, feiert am 29.3.91 seinen 65. Geburtstag.

\section{SATW Schweizerische Akademie der Technischen Wissenschaften}

Vorschau auf Veranstaltungen in der HEUREKA, dernationalen Forschungsausstellung zum 700 jährigen Bestehen derEidgenossenschaft, Allmend Brunau, Zürich-Enge

Kolloquium der 4 Akademien: "Freiheit und Grenzen der Forschung"

Die Konferenz der Schweizerischen Wissenschaftlichen Akademien wird am Freitag, den 24. Mai 1991 im Rahmen der Nationalen Forschungsausstellung «Heureka» in Zürich ein Kolloquium unter dem Generaltitel «Freiheit und Grenzen der Forschung» durchführen.

Tagung der SATW:

Samstag 22. Juni 1990

Nobelpreisträger stellen sich vor been harmonized with other previously published IUPAC documents.

Comments on the document are welcome and should be sent by 31 st October 1991 to:

G. Svehla, Department of Chemistry, University College Cork, Cork, Ireland.
Die SATW möchte mit dieser Tagung einer breiten Öffentlichkeit die Technik, ihre Ziele und Leistungen näher bringen und den Dialog mit der Allgemeinheit suchen und festigen. Die 4 Nobelpreistriger Prof.WernerAsber (Medizin 1978), Prof. Robert Huber (Chemie, 1988), Prof.K.AlexMïller, (Physik, 1987), Dr. Heinrich Rohrer (Physik 1986) haben als Referenten zugesagt. Als Moderatoren werden wirken Direktor $F$. Sutter (ASCOM Holding AG Bern) und Prof. Heimrich Ur. sprung (Direktor der Gruppe für Wissenschaft und Forschung im Eidg. Departement des Innern).

Als Panel-Mitglieder haben zugesagt für die Vorträge «Biologic, Medizin und Chemie» Dr. Hans Jucker, Delegierter des Verwal- 


\section{Branche Chemie setzt sich Leitplanken zur Gentechnik}

Die Schweizerische Gesellschaft für Chemische Industrie (SGCI) hat soeben die «Leitlinen zur Gentechnik" publiziert, die sich die auf diesem Gebiet tätigen Chemiefirmen in der Schweiz gegeben haben. Die Gentechnik zählt zu den Schlüsseltechnologien der Zukunft, weil sie neue Möglichkeiten eröffnet für die Erforschung und Therapie von bisher unbehandelbaren Krankheiten, für die Erzeugung von Nahrungsmitteln, für die Verbesserung des Pflanzenschutzes, sowie für die Entwicklung von energiesparenden und umweltschonenden Produktionsverfahren.

Die chemische und pharmazeutische Industrie der Schweiz will sich deshalb die Methoden der Gentechnik zunutze machen. Sie hat für den verantwortungsvollen Umgang mit dieser Technik die nachstehenden Leitlinien erarbeitet, die sie befolgen will:

\section{SGCl-Leitlinien zur Gentechnik}

Die Schweizerische Gesellschaft für Chemische Industrie (SGCI) betrachtet die Gentechnik als eine Schlüsseltechnologie der Zukunft.

Die Gentechnik ist von grossem Nutzen und trägt dazu bei,

- Krankheiten und ihre Ursachen zu erforschen und mit diesen Erkenntnissen präzisere diagnostische Methoden, wirksamere Arzneimittel und neue Wirkstoffe für die Gesundheit von Mensch und Tier zu entwickeln und herzustellen,

- die Nahrungsmittelerzeugung zu verbessern, landwirtschaftliche Methoden weiterzuentwickeln und den Pflanzenschutz gezielter und effizienter zu gestalten,

- Energie und Ressourcen zu sparen und umweltfreundliche Produktionsverfahren durch den Einsatz biotechnischer Prozesse zu entwickeln.

Die SGCI empfiehlt ihren Mitgliedern, Grundsätze der firmeneigenen Politik im Bereich der Gentechnik zu erstellen und regelmässig zu überprüfen. Zusätzlich sind Verfahren zu deren Implementierung, Aktualisierung und Kontrolle auszuarbeiten.

Verantwortung

Die Unternehmen der SGCI fördern und pflegen das Verständnis für ein verantwortliches Handeln bei den in diesem Bereich tätigen Mitarbeiterinnen und Mitarbeiter aller Stufen durch Aus- und Weiterbildung sowie durch geeignete Massnahmen im Bereich des Arbeitsschutzes.

\section{Sicherheit}

Beim Einsatz von genetischen Methoden sowie bei der Beurteilung der Risiken haben die Sicherheit der Mitarbeiterinnen und Mitarbeiter, von Mensch und Tier allgemein, sowie der Schutz der Umwelt Priorität.

\section{Ethische Grenzen}

Die Unternehmen der SGCI lassen sich von ethischen Wertvorstellungen leiten. Sie befassen sich nicht mit genetischen Veränderungen des Erbgutes in menschlichen Keimbahnzellen und in menschlichen Embryonen.

\section{Internationale Standards}

Die Unternehmen der SGCI wenden in der Beurteilung der gentechnischen Forschung und ihren Anwendungen die international anerkannten Empfehlungen der OECD und die Richtlinien der amerikanischen National Institutes of Health (NIH) an. Solange keine detaillierte gesetzliche Regelung besteht, registrieren sie gentechnische Forschungsvorhaben bei der «Interdisziplinären schweizerischen Kommission für biologische Sicherheit (SKBS)».

\section{Gesetzgebung}

Die Unternehmen der SGCI befürworten eine Oberaufsicht des Bundes über die «Interdisziplinäre schweizerische Kommission für biologische Sicherheit»"sowie die Anpassung der bestehenden Gesetzgebung auf Bundesebene zur Verhinderung von Missbräuchen und zum Schutz der Persönlichkeit sowie allgemein von Mensch und Umwelt.

\section{Information}

Eine breite und offene Information der Öffentlichkeit über die Chancen und die möglichen Probleme der Gentechnik ist notwendig. Die Unternehmen der SGCI bemühen sich um grösstmögliche Transparenz über ihre konkreten Tätigkeiten und Absichten im Bereich der Gentechnik. Sie unterstützen soweit als möglich die Bemühungen der Wissenschaftlerinnen und Wissenschaftler, allgemein verständlich und sachlich über die neuen Entwicklungen in diesem Forschungsbereich sowie über die Gesamtzusammenhänge zu informieren.

\section{Personalia}

\section{Geburtstage}

Karl G. Scheibli,

Dr. sc. techn., Bottmingen, Mitglied des SChV, feiert am 2.3.91 seinen 65 . Geburtstag.

\section{Albert Strüby,}

Chemiker HTL, Spiez, Mitglied des SChV, feiert am 3.3.91 seinen 65. Geburtstag.

Werner Weber,

Prof. Dr. sc. nat, St. Gallen, Mitglied des SChV, feiert an 6.3.91 seinen 80 . Geburtstag.

Hans Süss,

Chemiker HTL, Untersiggenthal, Mitglied des SChV, feiert am 10.3.91 seinen 70 . Geburtstag.

\section{Neue Mitglieder}

Lucas Auer, Bellevuestrasse 131, 3028 Spiegel

Urs Glättli, Rotackerstrasse 29, 8304 Wallisellen

Antonio Pessina, Dr. sc. nat., 6853 Ligornetto

\section{SYNOPOSIS}

\section{Nomenclature of kinetic}

methods of analysis

The report lists, in alphabetical order, names and definitions of 41 terms, most widely used in kinetic methods of analysis. These include kinetic, differential-kinetic, catalytic and enzymatic terms. They have
Ernst Schumacher-Christ,

Prof. Dr., Bremgarten, Mitglied des SChV, feiert am 12.3.91 seinen 65. Geburtstag

Werner Zimmermann, Chemiker HTL, Riehen, Mitglied des SChV, feiert am 17.3.91 seinen 65. Geburtstag.

Andreas Gïumann.

Dr. phil. II, Feldmeilen, Mitglied des SChV, feiert am 23.3.91 seinen 70. Geburtstag.

Alex Caspi

Chemiker HTL, Basel, Mitglied des SChV, feiert am 29.3.91 seinen 65. Geburtstag.

\section{SATW Schweizerische Akademie der Technischen Wissenschaften}

Vorschau auf Veranstaltungen in der HEUREKA, dernationalen Forschungsausstellung zum 700 jährigen Bestehen derEidgenossenschaft, Allmend Brunau, Zürich-Enge

Kolloquium der 4 Akademien: "Freiheit und Grenzen der Forschung"

Die Konferenz der Schweizerischen Wissenschaftlichen Akademien wird am Freitag, den 24. Mai 1991 im Rahmen der Nationalen Forschungsausstellung «Heureka» in Zürich ein Kolloquium unter dem Generaltitel «Freiheit und Grenzen der Forschung» durchführen.

Tagung der SATW:

Samstag 22. Juni 1990

Nobelpreisträger stellen sich vor been harmonized with other previously published IUPAC documents.

Comments on the document are welcome and should be sent by 31 st October 1991 to:

G. Svehla, Department of Chemistry, University College Cork, Cork, Ireland.
Die SATW möchte mit dieser Tagung einer breiten Öffentlichkeit die Technik, ihre Ziele und Leistungen näher bringen und den Dialog mit der Allgemeinheit suchen und festigen. Die 4 Nobelpreistriger Prof.WernerAsber (Medizin 1978), Prof. Robert Huber (Chemie, 1988), Prof.K.AlexMïller, (Physik, 1987), Dr. Heinrich Rohrer (Physik 1986) haben als Referenten zugesagt. Als Moderatoren werden wirken Direktor $F$. Sutter (ASCOM Holding AG Bern) und Prof. Heimrich Ur. sprung (Direktor der Gruppe für Wissenschaft und Forschung im Eidg. Departement des Innern).

Als Panel-Mitglieder haben zugesagt für die Vorträge «Biologic, Medizin und Chemie» Dr. Hans Jucker, Delegierter des Verwal- 
tungsrates der Alusuisse-Lonza Holding AG und Dr. Alex Krauer, Prïsident des Verwaltungsrates der Ciba-Geigy AG, Basel, für die Vorträge Physik Dr. T.P. Gasser, Mitglied der Konzernleitung der Asea Brown Boveri AG, Baden und Dr.

F. Fahrni, Präsident der Konzernleitung der Gebrüder Sulzer AG, Winterthur

(Ab $18.30 \mathrm{~h}$ voraussichtlich geschlossener Teil für Teilnehmer, Moderatoren, Vorstand, WBR und Gäste der SATW.)

\section{Hewlett-Packard weiterhin auf Wachstumskurs}

Hewlett-Packard meldet für das im Oktober abgeschlossene $\mathrm{Ge}$ schäftsjahr 1990 ein anhaltend starkes Wachstum. Trotz schwacher Konjunktur in der Computerindustrie konnten Bestellungseingang und Umsatz gesteigert werden.

Der Bestellungseingang erreichte weltweit 13.5 Milliarden Dollar. Dies sind $11 \%$ mehr als im Vorjahr. Der Umsatz stieg ebenfalls um $11 \%$ auf I3.2 Milliarden Dollar. Der Reingewinn des Unternehmens reduzierte sich auf 733 Millionen Dollar, das sind $11 \%$ weniger als im Vorjahr.
Die Schweizer Niederlassung erzielte ein Umsatzwachstum von $22 \%$ auf 376.1 Millionen Franken. Der Bestellungseingang nahm um 24\% auf 373.8 Millionen Franken zu. Der Mitarbeiterbestand der HewlettPackard (Schweiz) AG betrug per Ende Oktober 524, eine Zunahme um $11 \%$. Der pro Kopf Umsatz erhöhte sich von 650 Tausend Franken auf 718 Tausend Franken. $\mathrm{Zu}$ sammen mit dem europäischen Hauptsitz in Genf beschäftigt Hewlett-Packard in der Schweiz über l'000 Mitarbeiter.
Gruppe erwirtschaftete 1989 ca. 40 Mio. DM Umsatz und beschäftigt 140 Mitarbeiter.

Auf den 1. Januar 1991 wird Dr. G. Illing sen., der Gründer und bisherige Leiter der Firma, nach Erreichen der Altersgrenze in den Ruhestand treten. An seiner Stelle wird R. Schopp, bisher Mitarbeiter bei der zur EMS-Gruppe gehörenden Anlagenbaufirma EMS-INVENTA $A G$, die Geschäftsleitung übernehmen. Dr. G. Illing sen. wird der nächsten Generalversammlung der EMS-CHEMIE HOLDING AG zur Wahl in den Verwaltungsrat vorgeschlagen werden.

Die in der EMS-CHEMIE HOLDING AG Domat/Ems (Schweiz) zusammengeschlossene

EMS- führt.

\section{Innovationspreis für umweltfreundliches Verfahren zur} Wiederverwertung von Altpapier

Dem Chemieunternehmen van Baerle \& Cie AG, Münchenstein, wurde kürzlich der Innovationspreis 1990 beider Basel in Höhe von 20 '000 Franken für ein zukunfts-

weisendes, umweltfreundliches $\mathrm{Pa}$ pierleimungsverfahren zuerkannt, welches bei der Herstellung von Recyclingpapier und -Karton zur Anwendung koinmt.

\section{Gesellschaft Deutscher Chemiker jetzt für Gesamtdeutschland zuständig}

Die ehemalige Chemische Gesellschaft der DDR, die sich im Herbst 1990 in Chemische Gesellschafte. V. umbenannte, wurde zum 1. Januar mit der Gesellschaft Deutscher Chemiker (GDCh) vereinigt. Nachdem unmittelbar nach der «Wende» zunächst eine kooperative Zusammenarbeit vereinbart und erfolgreich mit dem Ziel begonnen wurde, die Vereinigung zu einem angemessenen Zeitpunkt zu realisieren, hat sich die Chemische Gesellschaft e. V. zu diesem Zwecke zum 31. Dezember 1990 aufgelöst. lhre Mitglieder werden Mitglieder der Gesellschaft Deutscher Chemiker.

Wie der Hauptgeschäftsführer der GDCh, Dr. Wolfgang Fritsche mitteilte, kann von einer «Wiedervereinigung» gesprochen werden; denn beide Gesellschaften traten nach dem Ende des 2. Weltkrieges die Traditionsnachfolge der 1867 gegründeten Deutschen Chemischen Gesellschaft und des 1887 gegründeten Vereins Deutscher Chemiker an.

Die Gesellschaft Deutscher Chemiker, schon immer eine der größten und angesehensten wissenschaftlichen Gesellschaften auf dem Gebiet der Chemie in der Welt, wird durch den Mitgliederzuwachs auf nun $25^{\prime} 000$ bis $26^{\prime} 000$ ein noch gröBeres Gewicht erlangen.

Zur Betreuung der Aktivitäten der Gesellschaft Deutscher Chemiker in den fünf neuen $B$ undesländern wurde in Berlin eine Außenstelle der Frankfurter GDCh-Geschäftsstelle eingerichtet.

\section{EMS-CHEMIE HOLDING AG übernimmt die deutsche} Dr. Illing GmbH \& Co. KG zu $100 \%$

Die EMS-CHEMIE HOLDING AG, Domat/Ems (Schweiz), welche bereits seit $1989 \mathrm{zu} 74 \%$ Miteigentiimerin der Dr. Illing GmbH \& Co. KG. Makromolekulare und Pharmazeutische Chemie, in Gross Umstadt ist, wird auf Januar 1991 auch den restlichen $26 \%$-igen Anteil an dieser Gesellschaft übernehrnen. Damit wird Illing zu $100 \%$ in den Besitz von EMS übergehen.

Die Dr. Illing-Gruppe gehört in Europa zu den bedeutenden konzernunabhängigen Herstellern für technische Kunststoffe und ist spezialisiert auf Polyamid- und Polyester-Legierungen, die sie nach eigenem Verfahren herstellt und veredelt. Ihre Spezialitäten werden unter den Markennamen Polyloy, IIlandur, Illen, Illenoy und Illexon vertrieben. Die Produkte, die hohes Ansehen geniessen, werden vor allem in der Automobilindustrie und ihren Zulieferern sowie der Elektround Elektronikindustrie abgesetzt zum überwiegenden Teil in Deutschland selbst. Die Illing-

\section{Die Schweizerische Gesellschaft für Chemische Industrie (SGCl) nimmt Stellung zum Revisionsentwurf des Umweltschutzgesetzes (USG)}

Die Schweizerische Gesellschaft für Chemische Industrie (SGCI) beurteilt in ihrer Stellungnahme die Vorschläge im Bereich der gentechnisch veränderten Organismen positiv. Im Bereich «Abfälle» kann sie sich mit den meisten ergänzenden Bestimmungen einverstanden erklären und begrüsst griffige Entscheide im Entsorgungsbereich. Dagegen lehnt sie die Förderungskompetenz des Bundes für die Entwicklung von Unwelttechnologien ab, weil die staatliche Förderung solcher Technologien ein interventionistisches Instrument darstellt.

Die Einführung marktkonforme Instrumente im Umweltschutz wird von der SGCI grundsätzlich begrüsst. Die konkreten Vorschläge zum Einsatz von Lenkungsabgaben in den vier vorgeschlagenen Gebieten werden von der SGCI hingegen abgelehnt, weil sie ihren Kriterien für den Einsatz von Lenkungsabgaben nicht genügen. Angesichts des unbestrittenen Handlungsbedarfs bei flüchtigen organischen Verbindungen (VOC) ist die SGCI bereit, zusammen mit den Behörden eine marktkonforme Lösung zur Verminderung dieser Emissionen zu erarbeiten. In den Bereichen «Pflanzenbehandlungsmittel», «Handelsdünger» sowie «Heizöl extraleicht und Dieselöl» lehnt die SGCI die vorgeschlagenen Lenkungsabgaben ab.

\section{European Summer School in Quantum Chemistry} (ESQC-91)

Tjörnarp Conference Centre, Sweden, August 18 - September 1 , 1991

Organized by the Department of Theoretical Chemistry, University of Lund, Sweden, and the Institute of Theoretical Physics, University of Stockholm, Sweden. The emphasis of the school will be more on understanding than on the technical aspects of the methods of quantum chemistry, and much time will be devoted to the discussion of different electronic structure problems and the choice of appropriate methods for their solution. The course will consist of both lectures and exercices. Lectures by J. Almlöf, T.U. Helgaker, P. Malmquist, J. Olsen, B.O. Roos, A.J. Sadlej, P.E.M. Siegbahn, P.R. Taylor, and U. Wahlgren. For further information, contact: Prof. B. Roos, Dept. of Theoretical Chemistry, Chemical Centre, P.O.Box 124, S-22100 Lund, Sweden (Tel: 46/46/108.251; EM: TEOBOR@HELIOS.LTH.SE) 
tungsrates der Alusuisse-Lonza Holding AG und Dr. Alex Krauer, Prïsident des Verwaltungsrates der Ciba-Geigy AG, Basel, für die Vorträge Physik Dr. T.P. Gasser, Mitglied der Konzernleitung der Asea Brown Boveri AG, Baden und Dr.

F. Fahrni, Präsident der Konzernleitung der Gebrüder Sulzer AG, Winterthur

(Ab $18.30 \mathrm{~h}$ voraussichtlich geschlossener Teil für Teilnehmer, Moderatoren, Vorstand, WBR und Gäste der SATW.)

\section{Hewlett-Packard weiterhin auf Wachstumskurs}

Hewlett-Packard meldet für das im Oktober abgeschlossene $\mathrm{Ge}$ schäftsjahr 1990 ein anhaltend starkes Wachstum. Trotz schwacher Konjunktur in der Computerindustrie konnten Bestellungseingang und Umsatz gesteigert werden.

Der Bestellungseingang erreichte weltweit 13.5 Milliarden Dollar. Dies sind $11 \%$ mehr als im Vorjahr. Der Umsatz stieg ebenfalls um $11 \%$ auf I3.2 Milliarden Dollar. Der Reingewinn des Unternehmens reduzierte sich auf 733 Millionen Dollar, das sind $11 \%$ weniger als im Vorjahr.
Die Schweizer Niederlassung erzielte ein Umsatzwachstum von $22 \%$ auf 376.1 Millionen Franken. Der Bestellungseingang nahm um 24\% auf 373.8 Millionen Franken zu. Der Mitarbeiterbestand der HewlettPackard (Schweiz) AG betrug per Ende Oktober 524, eine Zunahme um $11 \%$. Der pro Kopf Umsatz erhöhte sich von 650 Tausend Franken auf 718 Tausend Franken. $\mathrm{Zu}$ sammen mit dem europäischen Hauptsitz in Genf beschäftigt Hewlett-Packard in der Schweiz über l'000 Mitarbeiter.
Gruppe erwirtschaftete 1989 ca. 40 Mio. DM Umsatz und beschäftigt 140 Mitarbeiter.

Auf den 1. Januar 1991 wird Dr. G. Illing sen., der Gründer und bisherige Leiter der Firma, nach Erreichen der Altersgrenze in den Ruhestand treten. An seiner Stelle wird R. Schopp, bisher Mitarbeiter bei der zur EMS-Gruppe gehörenden Anlagenbaufirma EMS-INVENTA $A G$, die Geschäftsleitung übernehmen. Dr. G. Illing sen. wird der nächsten Generalversammlung der EMS-CHEMIE HOLDING AG zur Wahl in den Verwaltungsrat vorgeschlagen werden.

Die in der EMS-CHEMIE HOLDING AG Domat/Ems (Schweiz) zusammengeschlossene

EMS- führt.

\section{Innovationspreis für umweltfreundliches Verfahren zur} Wiederverwertung von Altpapier

Dem Chemieunternehmen van Baerle \& Cie AG, Münchenstein, wurde kürzlich der Innovationspreis 1990 beider Basel in Höhe von 20 '000 Franken für ein zukunfts-

weisendes, umweltfreundliches $\mathrm{Pa}$ pierleimungsverfahren zuerkannt, welches bei der Herstellung von Recyclingpapier und -Karton zur Anwendung koinmt.

\section{Gesellschaft Deutscher Chemiker jetzt für Gesamtdeutschland zuständig}

Die ehemalige Chemische Gesellschaft der DDR, die sich im Herbst 1990 in Chemische Gesellschafte. V. umbenannte, wurde zum 1. Januar mit der Gesellschaft Deutscher Chemiker (GDCh) vereinigt. Nachdem unmittelbar nach der «Wende» zunächst eine kooperative Zusammenarbeit vereinbart und erfolgreich mit dem Ziel begonnen wurde, die Vereinigung zu einem angemessenen Zeitpunkt zu realisieren, hat sich die Chemische Gesellschaft e. V. zu diesem Zwecke zum 31. Dezember 1990 aufgelöst. lhre Mitglieder werden Mitglieder der Gesellschaft Deutscher Chemiker.

Wie der Hauptgeschäftsführer der GDCh, Dr. Wolfgang Fritsche mitteilte, kann von einer «Wiedervereinigung» gesprochen werden; denn beide Gesellschaften traten nach dem Ende des 2. Weltkrieges die Traditionsnachfolge der 1867 gegründeten Deutschen Chemischen Gesellschaft und des 1887 gegründeten Vereins Deutscher Chemiker an.

Die Gesellschaft Deutscher Chemiker, schon immer eine der größten und angesehensten wissenschaftlichen Gesellschaften auf dem Gebiet der Chemie in der Welt, wird durch den Mitgliederzuwachs auf nun $25^{\prime} 000$ bis $26^{\prime} 000$ ein noch gröBeres Gewicht erlangen.

Zur Betreuung der Aktivitäten der Gesellschaft Deutscher Chemiker in den fünf neuen $B$ undesländern wurde in Berlin eine Außenstelle der Frankfurter GDCh-Geschäftsstelle eingerichtet.

\section{EMS-CHEMIE HOLDING AG übernimmt die deutsche} Dr. Illing GmbH \& Co. KG zu $100 \%$

Die EMS-CHEMIE HOLDING AG, Domat/Ems (Schweiz), welche bereits seit $1989 \mathrm{zu} 74 \%$ Miteigentiimerin der Dr. Illing GmbH \& Co. KG. Makromolekulare und Pharmazeutische Chemie, in Gross Umstadt ist, wird auf Januar 1991 auch den restlichen $26 \%$-igen Anteil an dieser Gesellschaft übernehrnen. Damit wird Illing zu $100 \%$ in den Besitz von EMS übergehen.

Die Dr. Illing-Gruppe gehört in Europa zu den bedeutenden konzernunabhängigen Herstellern für technische Kunststoffe und ist spezialisiert auf Polyamid- und Polyester-Legierungen, die sie nach eigenem Verfahren herstellt und veredelt. Ihre Spezialitäten werden unter den Markennamen Polyloy, IIlandur, Illen, Illenoy und Illexon vertrieben. Die Produkte, die hohes Ansehen geniessen, werden vor allem in der Automobilindustrie und ihren Zulieferern sowie der Elektround Elektronikindustrie abgesetzt zum überwiegenden Teil in Deutschland selbst. Die Illing-

\section{Die Schweizerische Gesellschaft für Chemische Industrie (SGCl) nimmt Stellung zum Revisionsentwurf des Umweltschutzgesetzes (USG)}

Die Schweizerische Gesellschaft für Chemische Industrie (SGCI) beurteilt in ihrer Stellungnahme die Vorschläge im Bereich der gentechnisch veränderten Organismen positiv. Im Bereich «Abfälle» kann sie sich mit den meisten ergänzenden Bestimmungen einverstanden erklären und begrüsst griffige Entscheide im Entsorgungsbereich. Dagegen lehnt sie die Förderungskompetenz des Bundes für die Entwicklung von Unwelttechnologien ab, weil die staatliche Förderung solcher Technologien ein interventionistisches Instrument darstellt.

Die Einführung marktkonforme Instrumente im Umweltschutz wird von der SGCI grundsätzlich begrüsst. Die konkreten Vorschläge zum Einsatz von Lenkungsabgaben in den vier vorgeschlagenen Gebieten werden von der SGCI hingegen abgelehnt, weil sie ihren Kriterien für den Einsatz von Lenkungsabgaben nicht genügen. Angesichts des unbestrittenen Handlungsbedarfs bei flüchtigen organischen Verbindungen (VOC) ist die SGCI bereit, zusammen mit den Behörden eine marktkonforme Lösung zur Verminderung dieser Emissionen zu erarbeiten. In den Bereichen «Pflanzenbehandlungsmittel», «Handelsdünger» sowie «Heizöl extraleicht und Dieselöl» lehnt die SGCI die vorgeschlagenen Lenkungsabgaben ab.

\section{European Summer School in Quantum Chemistry} (ESQC-91)

Tjörnarp Conference Centre, Sweden, August 18 - September 1 , 1991

Organized by the Department of Theoretical Chemistry, University of Lund, Sweden, and the Institute of Theoretical Physics, University of Stockholm, Sweden. The emphasis of the school will be more on understanding than on the technical aspects of the methods of quantum chemistry, and much time will be devoted to the discussion of different electronic structure problems and the choice of appropriate methods for their solution. The course will consist of both lectures and exercices. Lectures by J. Almlöf, T.U. Helgaker, P. Malmquist, J. Olsen, B.O. Roos, A.J. Sadlej, P.E.M. Siegbahn, P.R. Taylor, and U. Wahlgren. For further information, contact: Prof. B. Roos, Dept. of Theoretical Chemistry, Chemical Centre, P.O.Box 124, S-22100 Lund, Sweden (Tel: 46/46/108.251; EM: TEOBOR@HELIOS.LTH.SE) 
tungsrates der Alusuisse-Lonza Holding AG und Dr. Alex Krauer, Prïsident des Verwaltungsrates der Ciba-Geigy AG, Basel, für die Vorträge Physik Dr. T.P. Gasser, Mitglied der Konzernleitung der Asea Brown Boveri AG, Baden und Dr.

F. Fahrni, Präsident der Konzernleitung der Gebrüder Sulzer AG, Winterthur

(Ab $18.30 \mathrm{~h}$ voraussichtlich geschlossener Teil für Teilnehmer, Moderatoren, Vorstand, WBR und Gäste der SATW.)

\section{Hewlett-Packard weiterhin auf Wachstumskurs}

Hewlett-Packard meldet für das im Oktober abgeschlossene $\mathrm{Ge}$ schäftsjahr 1990 ein anhaltend starkes Wachstum. Trotz schwacher Konjunktur in der Computerindustrie konnten Bestellungseingang und Umsatz gesteigert werden.

Der Bestellungseingang erreichte weltweit 13.5 Milliarden Dollar. Dies sind $11 \%$ mehr als im Vorjahr. Der Umsatz stieg ebenfalls um $11 \%$ auf I3.2 Milliarden Dollar. Der Reingewinn des Unternehmens reduzierte sich auf 733 Millionen Dollar, das sind $11 \%$ weniger als im Vorjahr.
Die Schweizer Niederlassung erzielte ein Umsatzwachstum von $22 \%$ auf 376.1 Millionen Franken. Der Bestellungseingang nahm um 24\% auf 373.8 Millionen Franken zu. Der Mitarbeiterbestand der HewlettPackard (Schweiz) AG betrug per Ende Oktober 524, eine Zunahme um $11 \%$. Der pro Kopf Umsatz erhöhte sich von 650 Tausend Franken auf 718 Tausend Franken. $\mathrm{Zu}$ sammen mit dem europäischen Hauptsitz in Genf beschäftigt Hewlett-Packard in der Schweiz über l'000 Mitarbeiter.
Gruppe erwirtschaftete 1989 ca. 40 Mio. DM Umsatz und beschäftigt 140 Mitarbeiter.

Auf den 1. Januar 1991 wird Dr. G. Illing sen., der Gründer und bisherige Leiter der Firma, nach Erreichen der Altersgrenze in den Ruhestand treten. An seiner Stelle wird R. Schopp, bisher Mitarbeiter bei der zur EMS-Gruppe gehörenden Anlagenbaufirma EMS-INVENTA $A G$, die Geschäftsleitung übernehmen. Dr. G. Illing sen. wird der nächsten Generalversammlung der EMS-CHEMIE HOLDING AG zur Wahl in den Verwaltungsrat vorgeschlagen werden.

Die in der EMS-CHEMIE HOLDING AG Domat/Ems (Schweiz) zusammengeschlossene

EMS- führt.

\section{Innovationspreis für umweltfreundliches Verfahren zur} Wiederverwertung von Altpapier

Dem Chemieunternehmen van Baerle \& Cie AG, Münchenstein, wurde kürzlich der Innovationspreis 1990 beider Basel in Höhe von 20 '000 Franken für ein zukunfts-

weisendes, umweltfreundliches $\mathrm{Pa}$ pierleimungsverfahren zuerkannt, welches bei der Herstellung von Recyclingpapier und -Karton zur Anwendung koinmt.

\section{Gesellschaft Deutscher Chemiker jetzt für Gesamtdeutschland zuständig}

Die ehemalige Chemische Gesellschaft der DDR, die sich im Herbst 1990 in Chemische Gesellschafte. V. umbenannte, wurde zum 1. Januar mit der Gesellschaft Deutscher Chemiker (GDCh) vereinigt. Nachdem unmittelbar nach der «Wende» zunächst eine kooperative Zusammenarbeit vereinbart und erfolgreich mit dem Ziel begonnen wurde, die Vereinigung zu einem angemessenen Zeitpunkt zu realisieren, hat sich die Chemische Gesellschaft e. V. zu diesem Zwecke zum 31. Dezember 1990 aufgelöst. lhre Mitglieder werden Mitglieder der Gesellschaft Deutscher Chemiker.

Wie der Hauptgeschäftsführer der GDCh, Dr. Wolfgang Fritsche mitteilte, kann von einer «Wiedervereinigung» gesprochen werden; denn beide Gesellschaften traten nach dem Ende des 2. Weltkrieges die Traditionsnachfolge der 1867 gegründeten Deutschen Chemischen Gesellschaft und des 1887 gegründeten Vereins Deutscher Chemiker an.

Die Gesellschaft Deutscher Chemiker, schon immer eine der größten und angesehensten wissenschaftlichen Gesellschaften auf dem Gebiet der Chemie in der Welt, wird durch den Mitgliederzuwachs auf nun $25^{\prime} 000$ bis $26^{\prime} 000$ ein noch gröBeres Gewicht erlangen.

Zur Betreuung der Aktivitäten der Gesellschaft Deutscher Chemiker in den fünf neuen $B$ undesländern wurde in Berlin eine Außenstelle der Frankfurter GDCh-Geschäftsstelle eingerichtet.

\section{EMS-CHEMIE HOLDING AG übernimmt die deutsche} Dr. Illing GmbH \& Co. KG zu $100 \%$

Die EMS-CHEMIE HOLDING AG, Domat/Ems (Schweiz), welche bereits seit $1989 \mathrm{zu} 74 \%$ Miteigentiimerin der Dr. Illing GmbH \& Co. KG. Makromolekulare und Pharmazeutische Chemie, in Gross Umstadt ist, wird auf Januar 1991 auch den restlichen $26 \%$-igen Anteil an dieser Gesellschaft übernehrnen. Damit wird Illing zu $100 \%$ in den Besitz von EMS übergehen.

Die Dr. Illing-Gruppe gehört in Europa zu den bedeutenden konzernunabhängigen Herstellern für technische Kunststoffe und ist spezialisiert auf Polyamid- und Polyester-Legierungen, die sie nach eigenem Verfahren herstellt und veredelt. Ihre Spezialitäten werden unter den Markennamen Polyloy, IIlandur, Illen, Illenoy und Illexon vertrieben. Die Produkte, die hohes Ansehen geniessen, werden vor allem in der Automobilindustrie und ihren Zulieferern sowie der Elektround Elektronikindustrie abgesetzt zum überwiegenden Teil in Deutschland selbst. Die Illing-

\section{Die Schweizerische Gesellschaft für Chemische Industrie (SGCl) nimmt Stellung zum Revisionsentwurf des Umweltschutzgesetzes (USG)}

Die Schweizerische Gesellschaft für Chemische Industrie (SGCI) beurteilt in ihrer Stellungnahme die Vorschläge im Bereich der gentechnisch veränderten Organismen positiv. Im Bereich «Abfälle» kann sie sich mit den meisten ergänzenden Bestimmungen einverstanden erklären und begrüsst griffige Entscheide im Entsorgungsbereich. Dagegen lehnt sie die Förderungskompetenz des Bundes für die Entwicklung von Unwelttechnologien ab, weil die staatliche Förderung solcher Technologien ein interventionistisches Instrument darstellt.

Die Einführung marktkonforme Instrumente im Umweltschutz wird von der SGCI grundsätzlich begrüsst. Die konkreten Vorschläge zum Einsatz von Lenkungsabgaben in den vier vorgeschlagenen Gebieten werden von der SGCI hingegen abgelehnt, weil sie ihren Kriterien für den Einsatz von Lenkungsabgaben nicht genügen. Angesichts des unbestrittenen Handlungsbedarfs bei flüchtigen organischen Verbindungen (VOC) ist die SGCI bereit, zusammen mit den Behörden eine marktkonforme Lösung zur Verminderung dieser Emissionen zu erarbeiten. In den Bereichen «Pflanzenbehandlungsmittel», «Handelsdünger» sowie «Heizöl extraleicht und Dieselöl» lehnt die SGCI die vorgeschlagenen Lenkungsabgaben ab.

\section{European Summer School in Quantum Chemistry} (ESQC-91)

Tjörnarp Conference Centre, Sweden, August 18 - September 1 , 1991

Organized by the Department of Theoretical Chemistry, University of Lund, Sweden, and the Institute of Theoretical Physics, University of Stockholm, Sweden. The emphasis of the school will be more on understanding than on the technical aspects of the methods of quantum chemistry, and much time will be devoted to the discussion of different electronic structure problems and the choice of appropriate methods for their solution. The course will consist of both lectures and exercices. Lectures by J. Almlöf, T.U. Helgaker, P. Malmquist, J. Olsen, B.O. Roos, A.J. Sadlej, P.E.M. Siegbahn, P.R. Taylor, and U. Wahlgren. For further information, contact: Prof. B. Roos, Dept. of Theoretical Chemistry, Chemical Centre, P.O.Box 124, S-22100 Lund, Sweden (Tel: 46/46/108.251; EM: TEOBOR@HELIOS.LTH.SE) 
tungsrates der Alusuisse-Lonza Holding AG und Dr. Alex Krauer, Prïsident des Verwaltungsrates der Ciba-Geigy AG, Basel, für die Vorträge Physik Dr. T.P. Gasser, Mitglied der Konzernleitung der Asea Brown Boveri AG, Baden und Dr.

F. Fahrni, Präsident der Konzernleitung der Gebrüder Sulzer AG, Winterthur

(Ab $18.30 \mathrm{~h}$ voraussichtlich geschlossener Teil für Teilnehmer, Moderatoren, Vorstand, WBR und Gäste der SATW.)

\section{Hewlett-Packard weiterhin auf Wachstumskurs}

Hewlett-Packard meldet für das im Oktober abgeschlossene $\mathrm{Ge}$ schäftsjahr 1990 ein anhaltend starkes Wachstum. Trotz schwacher Konjunktur in der Computerindustrie konnten Bestellungseingang und Umsatz gesteigert werden.

Der Bestellungseingang erreichte weltweit 13.5 Milliarden Dollar. Dies sind $11 \%$ mehr als im Vorjahr. Der Umsatz stieg ebenfalls um $11 \%$ auf I3.2 Milliarden Dollar. Der Reingewinn des Unternehmens reduzierte sich auf 733 Millionen Dollar, das sind $11 \%$ weniger als im Vorjahr.
Die Schweizer Niederlassung erzielte ein Umsatzwachstum von $22 \%$ auf 376.1 Millionen Franken. Der Bestellungseingang nahm um 24\% auf 373.8 Millionen Franken zu. Der Mitarbeiterbestand der HewlettPackard (Schweiz) AG betrug per Ende Oktober 524, eine Zunahme um $11 \%$. Der pro Kopf Umsatz erhöhte sich von 650 Tausend Franken auf 718 Tausend Franken. $\mathrm{Zu}$ sammen mit dem europäischen Hauptsitz in Genf beschäftigt Hewlett-Packard in der Schweiz über l'000 Mitarbeiter.
Gruppe erwirtschaftete 1989 ca. 40 Mio. DM Umsatz und beschäftigt 140 Mitarbeiter.

Auf den 1. Januar 1991 wird Dr. G. Illing sen., der Gründer und bisherige Leiter der Firma, nach Erreichen der Altersgrenze in den Ruhestand treten. An seiner Stelle wird R. Schopp, bisher Mitarbeiter bei der zur EMS-Gruppe gehörenden Anlagenbaufirma EMS-INVENTA $A G$, die Geschäftsleitung übernehmen. Dr. G. Illing sen. wird der nächsten Generalversammlung der EMS-CHEMIE HOLDING AG zur Wahl in den Verwaltungsrat vorgeschlagen werden.

Die in der EMS-CHEMIE HOLDING AG Domat/Ems (Schweiz) zusammengeschlossene

EMS- führt.

\section{Innovationspreis für umweltfreundliches Verfahren zur} Wiederverwertung von Altpapier

Dem Chemieunternehmen van Baerle \& Cie AG, Münchenstein, wurde kürzlich der Innovationspreis 1990 beider Basel in Höhe von 20 '000 Franken für ein zukunfts-

weisendes, umweltfreundliches $\mathrm{Pa}$ pierleimungsverfahren zuerkannt, welches bei der Herstellung von Recyclingpapier und -Karton zur Anwendung koinmt.

\section{Gesellschaft Deutscher Chemiker jetzt für Gesamtdeutschland zuständig}

Die ehemalige Chemische Gesellschaft der DDR, die sich im Herbst 1990 in Chemische Gesellschafte. V. umbenannte, wurde zum 1. Januar mit der Gesellschaft Deutscher Chemiker (GDCh) vereinigt. Nachdem unmittelbar nach der «Wende» zunächst eine kooperative Zusammenarbeit vereinbart und erfolgreich mit dem Ziel begonnen wurde, die Vereinigung zu einem angemessenen Zeitpunkt zu realisieren, hat sich die Chemische Gesellschaft e. V. zu diesem Zwecke zum 31. Dezember 1990 aufgelöst. lhre Mitglieder werden Mitglieder der Gesellschaft Deutscher Chemiker.

Wie der Hauptgeschäftsführer der GDCh, Dr. Wolfgang Fritsche mitteilte, kann von einer «Wiedervereinigung» gesprochen werden; denn beide Gesellschaften traten nach dem Ende des 2. Weltkrieges die Traditionsnachfolge der 1867 gegründeten Deutschen Chemischen Gesellschaft und des 1887 gegründeten Vereins Deutscher Chemiker an.

Die Gesellschaft Deutscher Chemiker, schon immer eine der größten und angesehensten wissenschaftlichen Gesellschaften auf dem Gebiet der Chemie in der Welt, wird durch den Mitgliederzuwachs auf nun $25^{\prime} 000$ bis $26^{\prime} 000$ ein noch gröBeres Gewicht erlangen.

Zur Betreuung der Aktivitäten der Gesellschaft Deutscher Chemiker in den fünf neuen $B$ undesländern wurde in Berlin eine Außenstelle der Frankfurter GDCh-Geschäftsstelle eingerichtet.

\section{EMS-CHEMIE HOLDING AG übernimmt die deutsche} Dr. Illing GmbH \& Co. KG zu $100 \%$

Die EMS-CHEMIE HOLDING AG, Domat/Ems (Schweiz), welche bereits seit $1989 \mathrm{zu} 74 \%$ Miteigentiimerin der Dr. Illing GmbH \& Co. KG. Makromolekulare und Pharmazeutische Chemie, in Gross Umstadt ist, wird auf Januar 1991 auch den restlichen $26 \%$-igen Anteil an dieser Gesellschaft übernehrnen. Damit wird Illing zu $100 \%$ in den Besitz von EMS übergehen.

Die Dr. Illing-Gruppe gehört in Europa zu den bedeutenden konzernunabhängigen Herstellern für technische Kunststoffe und ist spezialisiert auf Polyamid- und Polyester-Legierungen, die sie nach eigenem Verfahren herstellt und veredelt. Ihre Spezialitäten werden unter den Markennamen Polyloy, IIlandur, Illen, Illenoy und Illexon vertrieben. Die Produkte, die hohes Ansehen geniessen, werden vor allem in der Automobilindustrie und ihren Zulieferern sowie der Elektround Elektronikindustrie abgesetzt zum überwiegenden Teil in Deutschland selbst. Die Illing-

\section{Die Schweizerische Gesellschaft für Chemische Industrie (SGCl) nimmt Stellung zum Revisionsentwurf des Umweltschutzgesetzes (USG)}

Die Schweizerische Gesellschaft für Chemische Industrie (SGCI) beurteilt in ihrer Stellungnahme die Vorschläge im Bereich der gentechnisch veränderten Organismen positiv. Im Bereich «Abfälle» kann sie sich mit den meisten ergänzenden Bestimmungen einverstanden erklären und begrüsst griffige Entscheide im Entsorgungsbereich. Dagegen lehnt sie die Förderungskompetenz des Bundes für die Entwicklung von Unwelttechnologien ab, weil die staatliche Förderung solcher Technologien ein interventionistisches Instrument darstellt.

Die Einführung marktkonforme Instrumente im Umweltschutz wird von der SGCI grundsätzlich begrüsst. Die konkreten Vorschläge zum Einsatz von Lenkungsabgaben in den vier vorgeschlagenen Gebieten werden von der SGCI hingegen abgelehnt, weil sie ihren Kriterien für den Einsatz von Lenkungsabgaben nicht genügen. Angesichts des unbestrittenen Handlungsbedarfs bei flüchtigen organischen Verbindungen (VOC) ist die SGCI bereit, zusammen mit den Behörden eine marktkonforme Lösung zur Verminderung dieser Emissionen zu erarbeiten. In den Bereichen «Pflanzenbehandlungsmittel», «Handelsdünger» sowie «Heizöl extraleicht und Dieselöl» lehnt die SGCI die vorgeschlagenen Lenkungsabgaben ab.

\section{European Summer School in Quantum Chemistry} (ESQC-91)

Tjörnarp Conference Centre, Sweden, August 18 - September 1 , 1991

Organized by the Department of Theoretical Chemistry, University of Lund, Sweden, and the Institute of Theoretical Physics, University of Stockholm, Sweden. The emphasis of the school will be more on understanding than on the technical aspects of the methods of quantum chemistry, and much time will be devoted to the discussion of different electronic structure problems and the choice of appropriate methods for their solution. The course will consist of both lectures and exercices. Lectures by J. Almlöf, T.U. Helgaker, P. Malmquist, J. Olsen, B.O. Roos, A.J. Sadlej, P.E.M. Siegbahn, P.R. Taylor, and U. Wahlgren. For further information, contact: Prof. B. Roos, Dept. of Theoretical Chemistry, Chemical Centre, P.O.Box 124, S-22100 Lund, Sweden (Tel: 46/46/108.251; EM: TEOBOR@HELIOS.LTH.SE) 
tungsrates der Alusuisse-Lonza Holding AG und Dr. Alex Krauer, Prïsident des Verwaltungsrates der Ciba-Geigy AG, Basel, für die Vorträge Physik Dr. T.P. Gasser, Mitglied der Konzernleitung der Asea Brown Boveri AG, Baden und Dr.

F. Fahrni, Präsident der Konzernleitung der Gebrüder Sulzer AG, Winterthur

(Ab $18.30 \mathrm{~h}$ voraussichtlich geschlossener Teil für Teilnehmer, Moderatoren, Vorstand, WBR und Gäste der SATW.)

\section{Hewlett-Packard weiterhin auf Wachstumskurs}

Hewlett-Packard meldet für das im Oktober abgeschlossene $\mathrm{Ge}$ schäftsjahr 1990 ein anhaltend starkes Wachstum. Trotz schwacher Konjunktur in der Computerindustrie konnten Bestellungseingang und Umsatz gesteigert werden.

Der Bestellungseingang erreichte weltweit 13.5 Milliarden Dollar. Dies sind $11 \%$ mehr als im Vorjahr. Der Umsatz stieg ebenfalls um $11 \%$ auf I3.2 Milliarden Dollar. Der Reingewinn des Unternehmens reduzierte sich auf 733 Millionen Dollar, das sind $11 \%$ weniger als im Vorjahr.
Die Schweizer Niederlassung erzielte ein Umsatzwachstum von $22 \%$ auf 376.1 Millionen Franken. Der Bestellungseingang nahm um 24\% auf 373.8 Millionen Franken zu. Der Mitarbeiterbestand der HewlettPackard (Schweiz) AG betrug per Ende Oktober 524, eine Zunahme um $11 \%$. Der pro Kopf Umsatz erhöhte sich von 650 Tausend Franken auf 718 Tausend Franken. $\mathrm{Zu}$ sammen mit dem europäischen Hauptsitz in Genf beschäftigt Hewlett-Packard in der Schweiz über l'000 Mitarbeiter.
Gruppe erwirtschaftete 1989 ca. 40 Mio. DM Umsatz und beschäftigt 140 Mitarbeiter.

Auf den 1. Januar 1991 wird Dr. G. Illing sen., der Gründer und bisherige Leiter der Firma, nach Erreichen der Altersgrenze in den Ruhestand treten. An seiner Stelle wird R. Schopp, bisher Mitarbeiter bei der zur EMS-Gruppe gehörenden Anlagenbaufirma EMS-INVENTA $A G$, die Geschäftsleitung übernehmen. Dr. G. Illing sen. wird der nächsten Generalversammlung der EMS-CHEMIE HOLDING AG zur Wahl in den Verwaltungsrat vorgeschlagen werden.

Die in der EMS-CHEMIE HOLDING AG Domat/Ems (Schweiz) zusammengeschlossene

EMS- führt.

\section{Innovationspreis für umweltfreundliches Verfahren zur} Wiederverwertung von Altpapier

Dem Chemieunternehmen van Baerle \& Cie AG, Münchenstein, wurde kürzlich der Innovationspreis 1990 beider Basel in Höhe von 20 '000 Franken für ein zukunfts-

weisendes, umweltfreundliches $\mathrm{Pa}$ pierleimungsverfahren zuerkannt, welches bei der Herstellung von Recyclingpapier und -Karton zur Anwendung koinmt.

\section{Gesellschaft Deutscher Chemiker jetzt für Gesamtdeutschland zuständig}

Die ehemalige Chemische Gesellschaft der DDR, die sich im Herbst 1990 in Chemische Gesellschafte. V. umbenannte, wurde zum 1. Januar mit der Gesellschaft Deutscher Chemiker (GDCh) vereinigt. Nachdem unmittelbar nach der «Wende» zunächst eine kooperative Zusammenarbeit vereinbart und erfolgreich mit dem Ziel begonnen wurde, die Vereinigung zu einem angemessenen Zeitpunkt zu realisieren, hat sich die Chemische Gesellschaft e. V. zu diesem Zwecke zum 31. Dezember 1990 aufgelöst. lhre Mitglieder werden Mitglieder der Gesellschaft Deutscher Chemiker.

Wie der Hauptgeschäftsführer der GDCh, Dr. Wolfgang Fritsche mitteilte, kann von einer «Wiedervereinigung» gesprochen werden; denn beide Gesellschaften traten nach dem Ende des 2. Weltkrieges die Traditionsnachfolge der 1867 gegründeten Deutschen Chemischen Gesellschaft und des 1887 gegründeten Vereins Deutscher Chemiker an.

Die Gesellschaft Deutscher Chemiker, schon immer eine der größten und angesehensten wissenschaftlichen Gesellschaften auf dem Gebiet der Chemie in der Welt, wird durch den Mitgliederzuwachs auf nun $25^{\prime} 000$ bis $26^{\prime} 000$ ein noch gröBeres Gewicht erlangen.

Zur Betreuung der Aktivitäten der Gesellschaft Deutscher Chemiker in den fünf neuen $B$ undesländern wurde in Berlin eine Außenstelle der Frankfurter GDCh-Geschäftsstelle eingerichtet.

\section{EMS-CHEMIE HOLDING AG übernimmt die deutsche} Dr. Illing GmbH \& Co. KG zu $100 \%$

Die EMS-CHEMIE HOLDING AG, Domat/Ems (Schweiz), welche bereits seit $1989 \mathrm{zu} 74 \%$ Miteigentiimerin der Dr. Illing GmbH \& Co. KG. Makromolekulare und Pharmazeutische Chemie, in Gross Umstadt ist, wird auf Januar 1991 auch den restlichen $26 \%$-igen Anteil an dieser Gesellschaft übernehrnen. Damit wird Illing zu $100 \%$ in den Besitz von EMS übergehen.

Die Dr. Illing-Gruppe gehört in Europa zu den bedeutenden konzernunabhängigen Herstellern für technische Kunststoffe und ist spezialisiert auf Polyamid- und Polyester-Legierungen, die sie nach eigenem Verfahren herstellt und veredelt. Ihre Spezialitäten werden unter den Markennamen Polyloy, IIlandur, Illen, Illenoy und Illexon vertrieben. Die Produkte, die hohes Ansehen geniessen, werden vor allem in der Automobilindustrie und ihren Zulieferern sowie der Elektround Elektronikindustrie abgesetzt zum überwiegenden Teil in Deutschland selbst. Die Illing-

\section{Die Schweizerische Gesellschaft für Chemische Industrie (SGCl) nimmt Stellung zum Revisionsentwurf des Umweltschutzgesetzes (USG)}

Die Schweizerische Gesellschaft für Chemische Industrie (SGCI) beurteilt in ihrer Stellungnahme die Vorschläge im Bereich der gentechnisch veränderten Organismen positiv. Im Bereich «Abfälle» kann sie sich mit den meisten ergänzenden Bestimmungen einverstanden erklären und begrüsst griffige Entscheide im Entsorgungsbereich. Dagegen lehnt sie die Förderungskompetenz des Bundes für die Entwicklung von Unwelttechnologien ab, weil die staatliche Förderung solcher Technologien ein interventionistisches Instrument darstellt.

Die Einführung marktkonforme Instrumente im Umweltschutz wird von der SGCI grundsätzlich begrüsst. Die konkreten Vorschläge zum Einsatz von Lenkungsabgaben in den vier vorgeschlagenen Gebieten werden von der SGCI hingegen abgelehnt, weil sie ihren Kriterien für den Einsatz von Lenkungsabgaben nicht genügen. Angesichts des unbestrittenen Handlungsbedarfs bei flüchtigen organischen Verbindungen (VOC) ist die SGCI bereit, zusammen mit den Behörden eine marktkonforme Lösung zur Verminderung dieser Emissionen zu erarbeiten. In den Bereichen «Pflanzenbehandlungsmittel», «Handelsdünger» sowie «Heizöl extraleicht und Dieselöl» lehnt die SGCI die vorgeschlagenen Lenkungsabgaben ab.

\section{European Summer School in Quantum Chemistry} (ESQC-91)

Tjörnarp Conference Centre, Sweden, August 18 - September 1 , 1991

Organized by the Department of Theoretical Chemistry, University of Lund, Sweden, and the Institute of Theoretical Physics, University of Stockholm, Sweden. The emphasis of the school will be more on understanding than on the technical aspects of the methods of quantum chemistry, and much time will be devoted to the discussion of different electronic structure problems and the choice of appropriate methods for their solution. The course will consist of both lectures and exercices. Lectures by J. Almlöf, T.U. Helgaker, P. Malmquist, J. Olsen, B.O. Roos, A.J. Sadlej, P.E.M. Siegbahn, P.R. Taylor, and U. Wahlgren. For further information, contact: Prof. B. Roos, Dept. of Theoretical Chemistry, Chemical Centre, P.O.Box 124, S-22100 Lund, Sweden (Tel: 46/46/108.251; EM: TEOBOR@HELIOS.LTH.SE) 
tungsrates der Alusuisse-Lonza Holding AG und Dr. Alex Krauer, Prïsident des Verwaltungsrates der Ciba-Geigy AG, Basel, für die Vorträge Physik Dr. T.P. Gasser, Mitglied der Konzernleitung der Asea Brown Boveri AG, Baden und Dr.

F. Fahrni, Präsident der Konzernleitung der Gebrüder Sulzer AG, Winterthur

(Ab $18.30 \mathrm{~h}$ voraussichtlich geschlossener Teil für Teilnehmer, Moderatoren, Vorstand, WBR und Gäste der SATW.)

\section{Hewlett-Packard weiterhin auf Wachstumskurs}

Hewlett-Packard meldet für das im Oktober abgeschlossene $\mathrm{Ge}$ schäftsjahr 1990 ein anhaltend starkes Wachstum. Trotz schwacher Konjunktur in der Computerindustrie konnten Bestellungseingang und Umsatz gesteigert werden.

Der Bestellungseingang erreichte weltweit 13.5 Milliarden Dollar. Dies sind $11 \%$ mehr als im Vorjahr. Der Umsatz stieg ebenfalls um $11 \%$ auf I3.2 Milliarden Dollar. Der Reingewinn des Unternehmens reduzierte sich auf 733 Millionen Dollar, das sind $11 \%$ weniger als im Vorjahr.
Die Schweizer Niederlassung erzielte ein Umsatzwachstum von $22 \%$ auf 376.1 Millionen Franken. Der Bestellungseingang nahm um 24\% auf 373.8 Millionen Franken zu. Der Mitarbeiterbestand der HewlettPackard (Schweiz) AG betrug per Ende Oktober 524, eine Zunahme um $11 \%$. Der pro Kopf Umsatz erhöhte sich von 650 Tausend Franken auf 718 Tausend Franken. $\mathrm{Zu}$ sammen mit dem europäischen Hauptsitz in Genf beschäftigt Hewlett-Packard in der Schweiz über l'000 Mitarbeiter.
Gruppe erwirtschaftete 1989 ca. 40 Mio. DM Umsatz und beschäftigt 140 Mitarbeiter.

Auf den 1. Januar 1991 wird Dr. G. Illing sen., der Gründer und bisherige Leiter der Firma, nach Erreichen der Altersgrenze in den Ruhestand treten. An seiner Stelle wird R. Schopp, bisher Mitarbeiter bei der zur EMS-Gruppe gehörenden Anlagenbaufirma EMS-INVENTA $A G$, die Geschäftsleitung übernehmen. Dr. G. Illing sen. wird der nächsten Generalversammlung der EMS-CHEMIE HOLDING AG zur Wahl in den Verwaltungsrat vorgeschlagen werden.

Die in der EMS-CHEMIE HOLDING AG Domat/Ems (Schweiz) zusammengeschlossene

EMS- führt.

\section{Innovationspreis für umweltfreundliches Verfahren zur} Wiederverwertung von Altpapier

Dem Chemieunternehmen van Baerle \& Cie AG, Münchenstein, wurde kürzlich der Innovationspreis 1990 beider Basel in Höhe von 20 '000 Franken für ein zukunfts-

weisendes, umweltfreundliches $\mathrm{Pa}$ pierleimungsverfahren zuerkannt, welches bei der Herstellung von Recyclingpapier und -Karton zur Anwendung koinmt.

\section{Gesellschaft Deutscher Chemiker jetzt für Gesamtdeutschland zuständig}

Die ehemalige Chemische Gesellschaft der DDR, die sich im Herbst 1990 in Chemische Gesellschafte. V. umbenannte, wurde zum 1. Januar mit der Gesellschaft Deutscher Chemiker (GDCh) vereinigt. Nachdem unmittelbar nach der «Wende» zunächst eine kooperative Zusammenarbeit vereinbart und erfolgreich mit dem Ziel begonnen wurde, die Vereinigung zu einem angemessenen Zeitpunkt zu realisieren, hat sich die Chemische Gesellschaft e. V. zu diesem Zwecke zum 31. Dezember 1990 aufgelöst. lhre Mitglieder werden Mitglieder der Gesellschaft Deutscher Chemiker.

Wie der Hauptgeschäftsführer der GDCh, Dr. Wolfgang Fritsche mitteilte, kann von einer «Wiedervereinigung» gesprochen werden; denn beide Gesellschaften traten nach dem Ende des 2. Weltkrieges die Traditionsnachfolge der 1867 gegründeten Deutschen Chemischen Gesellschaft und des 1887 gegründeten Vereins Deutscher Chemiker an.

Die Gesellschaft Deutscher Chemiker, schon immer eine der größten und angesehensten wissenschaftlichen Gesellschaften auf dem Gebiet der Chemie in der Welt, wird durch den Mitgliederzuwachs auf nun $25^{\prime} 000$ bis $26^{\prime} 000$ ein noch gröBeres Gewicht erlangen.

Zur Betreuung der Aktivitäten der Gesellschaft Deutscher Chemiker in den fünf neuen $B$ undesländern wurde in Berlin eine Außenstelle der Frankfurter GDCh-Geschäftsstelle eingerichtet.

\section{EMS-CHEMIE HOLDING AG übernimmt die deutsche} Dr. Illing GmbH \& Co. KG zu $100 \%$

Die EMS-CHEMIE HOLDING AG, Domat/Ems (Schweiz), welche bereits seit $1989 \mathrm{zu} 74 \%$ Miteigentiimerin der Dr. Illing GmbH \& Co. KG. Makromolekulare und Pharmazeutische Chemie, in Gross Umstadt ist, wird auf Januar 1991 auch den restlichen $26 \%$-igen Anteil an dieser Gesellschaft übernehrnen. Damit wird Illing zu $100 \%$ in den Besitz von EMS übergehen.

Die Dr. Illing-Gruppe gehört in Europa zu den bedeutenden konzernunabhängigen Herstellern für technische Kunststoffe und ist spezialisiert auf Polyamid- und Polyester-Legierungen, die sie nach eigenem Verfahren herstellt und veredelt. Ihre Spezialitäten werden unter den Markennamen Polyloy, IIlandur, Illen, Illenoy und Illexon vertrieben. Die Produkte, die hohes Ansehen geniessen, werden vor allem in der Automobilindustrie und ihren Zulieferern sowie der Elektround Elektronikindustrie abgesetzt zum überwiegenden Teil in Deutschland selbst. Die Illing-

\section{Die Schweizerische Gesellschaft für Chemische Industrie (SGCl) nimmt Stellung zum Revisionsentwurf des Umweltschutzgesetzes (USG)}

Die Schweizerische Gesellschaft für Chemische Industrie (SGCI) beurteilt in ihrer Stellungnahme die Vorschläge im Bereich der gentechnisch veränderten Organismen positiv. Im Bereich «Abfälle» kann sie sich mit den meisten ergänzenden Bestimmungen einverstanden erklären und begrüsst griffige Entscheide im Entsorgungsbereich. Dagegen lehnt sie die Förderungskompetenz des Bundes für die Entwicklung von Unwelttechnologien ab, weil die staatliche Förderung solcher Technologien ein interventionistisches Instrument darstellt.

Die Einführung marktkonforme Instrumente im Umweltschutz wird von der SGCI grundsätzlich begrüsst. Die konkreten Vorschläge zum Einsatz von Lenkungsabgaben in den vier vorgeschlagenen Gebieten werden von der SGCI hingegen abgelehnt, weil sie ihren Kriterien für den Einsatz von Lenkungsabgaben nicht genügen. Angesichts des unbestrittenen Handlungsbedarfs bei flüchtigen organischen Verbindungen (VOC) ist die SGCI bereit, zusammen mit den Behörden eine marktkonforme Lösung zur Verminderung dieser Emissionen zu erarbeiten. In den Bereichen «Pflanzenbehandlungsmittel», «Handelsdünger» sowie «Heizöl extraleicht und Dieselöl» lehnt die SGCI die vorgeschlagenen Lenkungsabgaben ab.

\section{European Summer School in Quantum Chemistry} (ESQC-91)

Tjörnarp Conference Centre, Sweden, August 18 - September 1 , 1991

Organized by the Department of Theoretical Chemistry, University of Lund, Sweden, and the Institute of Theoretical Physics, University of Stockholm, Sweden. The emphasis of the school will be more on understanding than on the technical aspects of the methods of quantum chemistry, and much time will be devoted to the discussion of different electronic structure problems and the choice of appropriate methods for their solution. The course will consist of both lectures and exercices. Lectures by J. Almlöf, T.U. Helgaker, P. Malmquist, J. Olsen, B.O. Roos, A.J. Sadlej, P.E.M. Siegbahn, P.R. Taylor, and U. Wahlgren. For further information, contact: Prof. B. Roos, Dept. of Theoretical Chemistry, Chemical Centre, P.O.Box 124, S-22100 Lund, Sweden (Tel: 46/46/108.251; EM: TEOBOR@HELIOS.LTH.SE) 
tungsrates der Alusuisse-Lonza Holding AG und Dr. Alex Krauer, Prïsident des Verwaltungsrates der Ciba-Geigy AG, Basel, für die Vorträge Physik Dr. T.P. Gasser, Mitglied der Konzernleitung der Asea Brown Boveri AG, Baden und Dr.

F. Fahrni, Präsident der Konzernleitung der Gebrüder Sulzer AG, Winterthur

(Ab $18.30 \mathrm{~h}$ voraussichtlich geschlossener Teil für Teilnehmer, Moderatoren, Vorstand, WBR und Gäste der SATW.)

\section{Hewlett-Packard weiterhin auf Wachstumskurs}

Hewlett-Packard meldet für das im Oktober abgeschlossene $\mathrm{Ge}$ schäftsjahr 1990 ein anhaltend starkes Wachstum. Trotz schwacher Konjunktur in der Computerindustrie konnten Bestellungseingang und Umsatz gesteigert werden.

Der Bestellungseingang erreichte weltweit 13.5 Milliarden Dollar. Dies sind $11 \%$ mehr als im Vorjahr. Der Umsatz stieg ebenfalls um $11 \%$ auf I3.2 Milliarden Dollar. Der Reingewinn des Unternehmens reduzierte sich auf 733 Millionen Dollar, das sind $11 \%$ weniger als im Vorjahr.
Die Schweizer Niederlassung erzielte ein Umsatzwachstum von $22 \%$ auf 376.1 Millionen Franken. Der Bestellungseingang nahm um 24\% auf 373.8 Millionen Franken zu. Der Mitarbeiterbestand der HewlettPackard (Schweiz) AG betrug per Ende Oktober 524, eine Zunahme um $11 \%$. Der pro Kopf Umsatz erhöhte sich von 650 Tausend Franken auf 718 Tausend Franken. $\mathrm{Zu}$ sammen mit dem europäischen Hauptsitz in Genf beschäftigt Hewlett-Packard in der Schweiz über l'000 Mitarbeiter.
Gruppe erwirtschaftete 1989 ca. 40 Mio. DM Umsatz und beschäftigt 140 Mitarbeiter.

Auf den 1. Januar 1991 wird Dr. G. Illing sen., der Gründer und bisherige Leiter der Firma, nach Erreichen der Altersgrenze in den Ruhestand treten. An seiner Stelle wird R. Schopp, bisher Mitarbeiter bei der zur EMS-Gruppe gehörenden Anlagenbaufirma EMS-INVENTA $A G$, die Geschäftsleitung übernehmen. Dr. G. Illing sen. wird der nächsten Generalversammlung der EMS-CHEMIE HOLDING AG zur Wahl in den Verwaltungsrat vorgeschlagen werden.

Die in der EMS-CHEMIE HOLDING AG Domat/Ems (Schweiz) zusammengeschlossene

EMS- führt.

\section{Innovationspreis für umweltfreundliches Verfahren zur} Wiederverwertung von Altpapier

Dem Chemieunternehmen van Baerle \& Cie AG, Münchenstein, wurde kürzlich der Innovationspreis 1990 beider Basel in Höhe von 20 '000 Franken für ein zukunfts-

weisendes, umweltfreundliches $\mathrm{Pa}$ pierleimungsverfahren zuerkannt, welches bei der Herstellung von Recyclingpapier und -Karton zur Anwendung koinmt.

\section{Gesellschaft Deutscher Chemiker jetzt für Gesamtdeutschland zuständig}

Die ehemalige Chemische Gesellschaft der DDR, die sich im Herbst 1990 in Chemische Gesellschafte. V. umbenannte, wurde zum 1. Januar mit der Gesellschaft Deutscher Chemiker (GDCh) vereinigt. Nachdem unmittelbar nach der «Wende» zunächst eine kooperative Zusammenarbeit vereinbart und erfolgreich mit dem Ziel begonnen wurde, die Vereinigung zu einem angemessenen Zeitpunkt zu realisieren, hat sich die Chemische Gesellschaft e. V. zu diesem Zwecke zum 31. Dezember 1990 aufgelöst. lhre Mitglieder werden Mitglieder der Gesellschaft Deutscher Chemiker.

Wie der Hauptgeschäftsführer der GDCh, Dr. Wolfgang Fritsche mitteilte, kann von einer «Wiedervereinigung» gesprochen werden; denn beide Gesellschaften traten nach dem Ende des 2. Weltkrieges die Traditionsnachfolge der 1867 gegründeten Deutschen Chemischen Gesellschaft und des 1887 gegründeten Vereins Deutscher Chemiker an.

Die Gesellschaft Deutscher Chemiker, schon immer eine der größten und angesehensten wissenschaftlichen Gesellschaften auf dem Gebiet der Chemie in der Welt, wird durch den Mitgliederzuwachs auf nun $25^{\prime} 000$ bis $26^{\prime} 000$ ein noch gröBeres Gewicht erlangen.

Zur Betreuung der Aktivitäten der Gesellschaft Deutscher Chemiker in den fünf neuen $B$ undesländern wurde in Berlin eine Außenstelle der Frankfurter GDCh-Geschäftsstelle eingerichtet.

\section{EMS-CHEMIE HOLDING AG übernimmt die deutsche} Dr. Illing GmbH \& Co. KG zu $100 \%$

Die EMS-CHEMIE HOLDING AG, Domat/Ems (Schweiz), welche bereits seit $1989 \mathrm{zu} 74 \%$ Miteigentiimerin der Dr. Illing GmbH \& Co. KG. Makromolekulare und Pharmazeutische Chemie, in Gross Umstadt ist, wird auf Januar 1991 auch den restlichen $26 \%$-igen Anteil an dieser Gesellschaft übernehrnen. Damit wird Illing zu $100 \%$ in den Besitz von EMS übergehen.

Die Dr. Illing-Gruppe gehört in Europa zu den bedeutenden konzernunabhängigen Herstellern für technische Kunststoffe und ist spezialisiert auf Polyamid- und Polyester-Legierungen, die sie nach eigenem Verfahren herstellt und veredelt. Ihre Spezialitäten werden unter den Markennamen Polyloy, IIlandur, Illen, Illenoy und Illexon vertrieben. Die Produkte, die hohes Ansehen geniessen, werden vor allem in der Automobilindustrie und ihren Zulieferern sowie der Elektround Elektronikindustrie abgesetzt zum überwiegenden Teil in Deutschland selbst. Die Illing-

\section{Die Schweizerische Gesellschaft für Chemische Industrie (SGCl) nimmt Stellung zum Revisionsentwurf des Umweltschutzgesetzes (USG)}

Die Schweizerische Gesellschaft für Chemische Industrie (SGCI) beurteilt in ihrer Stellungnahme die Vorschläge im Bereich der gentechnisch veränderten Organismen positiv. Im Bereich «Abfälle» kann sie sich mit den meisten ergänzenden Bestimmungen einverstanden erklären und begrüsst griffige Entscheide im Entsorgungsbereich. Dagegen lehnt sie die Förderungskompetenz des Bundes für die Entwicklung von Unwelttechnologien ab, weil die staatliche Förderung solcher Technologien ein interventionistisches Instrument darstellt.

Die Einführung marktkonforme Instrumente im Umweltschutz wird von der SGCI grundsätzlich begrüsst. Die konkreten Vorschläge zum Einsatz von Lenkungsabgaben in den vier vorgeschlagenen Gebieten werden von der SGCI hingegen abgelehnt, weil sie ihren Kriterien für den Einsatz von Lenkungsabgaben nicht genügen. Angesichts des unbestrittenen Handlungsbedarfs bei flüchtigen organischen Verbindungen (VOC) ist die SGCI bereit, zusammen mit den Behörden eine marktkonforme Lösung zur Verminderung dieser Emissionen zu erarbeiten. In den Bereichen «Pflanzenbehandlungsmittel», «Handelsdünger» sowie «Heizöl extraleicht und Dieselöl» lehnt die SGCI die vorgeschlagenen Lenkungsabgaben ab.

\section{European Summer School in Quantum Chemistry} (ESQC-91)

Tjörnarp Conference Centre, Sweden, August 18 - September 1 , 1991

Organized by the Department of Theoretical Chemistry, University of Lund, Sweden, and the Institute of Theoretical Physics, University of Stockholm, Sweden. The emphasis of the school will be more on understanding than on the technical aspects of the methods of quantum chemistry, and much time will be devoted to the discussion of different electronic structure problems and the choice of appropriate methods for their solution. The course will consist of both lectures and exercices. Lectures by J. Almlöf, T.U. Helgaker, P. Malmquist, J. Olsen, B.O. Roos, A.J. Sadlej, P.E.M. Siegbahn, P.R. Taylor, and U. Wahlgren. For further information, contact: Prof. B. Roos, Dept. of Theoretical Chemistry, Chemical Centre, P.O.Box 124, S-22100 Lund, Sweden (Tel: 46/46/108.251; EM: TEOBOR@HELIOS.LTH.SE) 
4th International Conference on the Applications of Density Functional Theory in Chemistry and Physics

Centro Stefano Franscini, Monte Verita, Ascona, Switzerland, September 23-29, 1991

Organized by C. Daul (University of Fribourg), M. Posternak (EPF Lausanne) and J. Weber (University of Geneva). The conference will treat all aspects of Density Functional Theory (DFT), with special attention being paid to applications in chemistry and physics, including: (i) electronic structure calculations and structural energy minimizations; (ii) calculation of chemical and physical properties; (iii) molecular dynamics and Car-Parrinello type DFT; (iv) new methodological developments in DFT and beyond. Lectures by J. Andzelm, E.J. Baerends, R. Car, H. Chermette, J.P. Daudey, R.O. Jones, E. Ludena, R.G. Parr, and M. Schluter. For further information, contact: $\mathrm{Dr}$. C. Daul, Institute of Inorganic Chemistry, University of Fribourg, Perolles, 1700Fribourg, Switzerland (Tel:037/82.64.36;EM:CDAUL@ CFRUNI52).

\section{Givaudan \& Cie SA}

Die L. Givaudan \& Cie SA in Genf, eine Tochtergesellschaft der Roche Holding AG in Basel, hat die Übernahme der Fritzsche Dodge \& Olcott(FDO), New York, und deren weltweiten Aktivitäten auf den 31. Dezember 1990, bekanntgegeben. FDO war bis heute im Besitz der BASF K\&F Corporation, einer Tochtergesellschaft der deutschen BASF AG, Ludwigshafen, Deutschland.

Die Acquisition ist in Übereinkunft mit dem schon früher bekanntgegebenen Abkommen. Zum Preis der Transaktion wurden keine Angaben gemacht.

Givaudan ist einer der führenden internationalen Hersteller von Aromen, Parfüms und Aromachemikalien und erzielte 1989 weltweit Verkäufe von 530 Mio US\$. FDO entwickelt, produziert und vertreibt Aromen- und Riechstoffe und wies 1989 einen Umsatz von 120.4 Mio.US\$ auf. Mit dieser Übernahme erschliessen sich Givaudan neue Absatzmöglichkeiten in den Segmenten der Lebensmittelindustrie und zusätzliche Verkäufe in den Bereichen der Parfümkompositio- nen und Aromachemikalien zur Herstellung von Kosmetika, Toilettenartikel und Haushaltprodukten.

Gemäss einem Integrationsplan, der aufgrund eines am 1. Januar 1991 beginnenden Evaluationsverfahrens erstellt wird, soll FDO mit Givaudan fusioniert werden. Die entsprechenden Integrationskomitees, die dieses Evaluationsverfahren durchführen werden, bestehen aus Mitgliedern beider Firmen in den USA sowie weiteren Ländern in denen FDO mit Filialen vertreten ist.

Diese Acquisition entspricht der von Roche verfolgten Strategie, sich auf ihre vier Aktivitätsbereiche zu konzentrieren: pharmazeutische Spezialitäten, Vitamine und Feinchemikalien, Diagnostika, sowie Riechstoffe und Aromen. Roche Holding $A G$ ist die Muttergesellschaft einer weltweit tätigen Gruppe forschender Unternehmen im Gesundheitswesen, deren Aktivitäten das ganze Spektrum von Vorbeugung, Erkenntnis und Behandlung von Krankheiten umfassen.

\section{Grammatikakis-Neumann Prize in Photochemistry}

In 1991, a Prize from the Grammatikakis-Neumann Fund of the European Photochemistry Association, Section Switzerland (Swiss Society of Photochemistry and Photophysics), will be awarded to a young research scientist for outstanding contributions in the field of photochemistry. The award followed by the lecture of the prizewinner is scheduled for October 1991, at the Annual Meeting of EPASwitzerland, Lausanne, Switzerland.
You are invited to submit nominations or applications including curriculum vitae, list of publications, reprints, and preprints to the president of the jury

Prof. Dr. Gion Calzaferri Inst. of Inorganic and Physical Chemistry

University of Bern

CH-3000 Bern 9

by June 1,1991 .

Beförderungen in der Industrie

CHIMIA 45 (1991) Nr.1/2 (Januar/Februar)

\section{Ciba-Geigy AG}

Der Verwaltungsrat und die Konzernleitung haben mit Wirkung ab

1. Januar 1991 folgende Ernennungen im Rahmen der Parallelhierarchie beschlossen:

Zu Wissenschaftlichen Experten

Dr. Hans-Ulrich Blaser

Dr. Satish Chandra Khanna

Dr. Cesare Mondadori

Dr. Burkhard Sechser

FD Katalyse und Synthesedienste

$\mathrm{PH}$ Forschung und Entwicklung

$\mathrm{PH}$ Forschung und Entwicklung

AG Forschung und Entwicklung Pflanzenschutz

Dr. Athanassios Tzikas

FC Forschung und Entwicklung

Zu einem Technischen Experten

Dr. Roland Bauhofer $\quad$ FC Marketing

Zu einem Experten für Informatik

Ulrich Gentsch, dipl. Math. IS Computer Communication Center

Zu Wissenschaftlichen Spezialisten

Willi Bättig, Chem. HTL

Dr. Nico Cerletti

Peter H. Degen, Chem. CG

Dr. Kurt Dietliker

Dr. John M. Ford

Dr. Dimiter Hadjistamov

Frau Dr. Kathleen Hauser

Dr. Christian Landes

Dr. Helmut Mett

Dr. Jin Mizuguchi

Dr. Dieter Nordmeyer

Dr. Udo Plüc

Frau Dr. Erika Schmidt

Dr. Thomas Schupp

Dr. Rolf Schurter

Rudolf Zink, Chem. CG

AG Produktion

PH Forschung und Entwicklung

$\mathrm{PH}$ Forschung und Entwicklung

$\mathrm{AD}$ Forschung

$\mathrm{PH}$ Forschung und Entwicklung

KU Technik

PH Forschung und Entwicklung

AG Toxikologie-Dienste

$\mathrm{PH}$ Forschung und Entwicklung

FO Materialforschung

AG Forschung und Entwicklung Pflanzenschutz

AG Forschung und Entwicklung Pflanzenschutz

FD Physik

$\mathrm{PH}$ Forschung und Entwicklung

AG Forschung und Entwicklung Pflanzenschutz

Zu Technischen Spezialisten

Rolf Günther, dipl. Ing.

Dr. Peter Oggenfuss

Dr. Gerhard Reinert

Dr. Theodor Steiner

August Tinner, Chem. HTL

FC Forschung und Entwicklung

Zu Spezialisten für Informatik

Gilbert Bastard, dipl. Ing.

Rene Burkhardt, dipl. Phys.

Boudewijn Coster

FC Marketing

AG Produktion

FC Forschung und Entwicklung

AG UB Tiergesundheit

KU Technik

Pierre Hasselmann, dipl. Ing.

Dr. Rainer Nutz

Alex Sele, Chem. CG

Willem Vaessen, M. Sc.

Toni Walch

WM Controle et informatique

IT Beratung

IS Applikationsentwicklung/ Materialwirtschaft

AG Planung, Information, Control und Divisionale Dienstleistungen

PH Regionen Management und PIC

PH Forschung und Entwicklung

PH Technik

IS Grossrechnertechnik

Zu Betriebswirtschaftlichen Spezialisten

Eduard Egger, Ing. grad.

Egon F. Ulshöfer
PH Regionen Management und PIC

PI Planung/Information / Control 
4th International Conference on the Applications of Density Functional Theory in Chemistry and Physics

Centro Stefano Franscini, Monte Verita, Ascona, Switzerland, September 23-29, 1991

Organized by C. Daul (University of Fribourg), M. Posternak (EPF Lausanne) and J. Weber (University of Geneva). The conference will treat all aspects of Density Functional Theory (DFT), with special attention being paid to applications in chemistry and physics, including: (i) electronic structure calculations and structural energy minimizations; (ii) calculation of chemical and physical properties; (iii) molecular dynamics and Car-Parrinello type DFT; (iv) new methodological developments in DFT and beyond. Lectures by J. Andzelm, E.J. Baerends, R. Car, H. Chermette, J.P. Daudey, R.O. Jones, E. Ludena, R.G. Parr, and M. Schluter. For further information, contact: $\mathrm{Dr}$. C. Daul, Institute of Inorganic Chemistry, University of Fribourg, Perolles, 1700Fribourg, Switzerland (Tel:037/82.64.36;EM:CDAUL@ CFRUNI52).

\section{Givaudan \& Cie SA}

Die L. Givaudan \& Cie SA in Genf, eine Tochtergesellschaft der Roche Holding AG in Basel, hat die Übernahme der Fritzsche Dodge \& Olcott(FDO), New York, und deren weltweiten Aktivitäten auf den 31. Dezember 1990, bekanntgegeben. FDO war bis heute im Besitz der BASF K\&F Corporation, einer Tochtergesellschaft der deutschen BASF AG, Ludwigshafen, Deutschland.

Die Acquisition ist in Übereinkunft mit dem schon früher bekanntgegebenen Abkommen. Zum Preis der Transaktion wurden keine Angaben gemacht.

Givaudan ist einer der führenden internationalen Hersteller von Aromen, Parfüms und Aromachemikalien und erzielte 1989 weltweit Verkäufe von 530 Mio US\$. FDO entwickelt, produziert und vertreibt Aromen- und Riechstoffe und wies 1989 einen Umsatz von 120.4 Mio.US\$ auf. Mit dieser Übernahme erschliessen sich Givaudan neue Absatzmöglichkeiten in den Segmenten der Lebensmittelindustrie und zusätzliche Verkäufe in den Bereichen der Parfümkompositio- nen und Aromachemikalien zur Herstellung von Kosmetika, Toilettenartikel und Haushaltprodukten.

Gemäss einem Integrationsplan, der aufgrund eines am 1. Januar 1991 beginnenden Evaluationsverfahrens erstellt wird, soll FDO mit Givaudan fusioniert werden. Die entsprechenden Integrationskomitees, die dieses Evaluationsverfahren durchführen werden, bestehen aus Mitgliedern beider Firmen in den USA sowie weiteren Ländern in denen FDO mit Filialen vertreten ist.

Diese Acquisition entspricht der von Roche verfolgten Strategie, sich auf ihre vier Aktivitätsbereiche zu konzentrieren: pharmazeutische Spezialitäten, Vitamine und Feinchemikalien, Diagnostika, sowie Riechstoffe und Aromen. Roche Holding $A G$ ist die Muttergesellschaft einer weltweit tätigen Gruppe forschender Unternehmen im Gesundheitswesen, deren Aktivitäten das ganze Spektrum von Vorbeugung, Erkenntnis und Behandlung von Krankheiten umfassen.

\section{Grammatikakis-Neumann Prize in Photochemistry}

In 1991, a Prize from the Grammatikakis-Neumann Fund of the European Photochemistry Association, Section Switzerland (Swiss Society of Photochemistry and Photophysics), will be awarded to a young research scientist for outstanding contributions in the field of photochemistry. The award followed by the lecture of the prizewinner is scheduled for October 1991, at the Annual Meeting of EPASwitzerland, Lausanne, Switzerland.
You are invited to submit nominations or applications including curriculum vitae, list of publications, reprints, and preprints to the president of the jury

Prof. Dr. Gion Calzaferri Inst. of Inorganic and Physical Chemistry

University of Bern

CH-3000 Bern 9

by June 1,1991 .

Beförderungen in der Industrie

CHIMIA 45 (1991) Nr.1/2 (Januar/Februar)

\section{Ciba-Geigy AG}

Der Verwaltungsrat und die Konzernleitung haben mit Wirkung ab

1. Januar 1991 folgende Ernennungen im Rahmen der Parallelhierarchie beschlossen:

Zu Wissenschaftlichen Experten

Dr. Hans-Ulrich Blaser

Dr. Satish Chandra Khanna

Dr. Cesare Mondadori

Dr. Burkhard Sechser

FD Katalyse und Synthesedienste

$\mathrm{PH}$ Forschung und Entwicklung

$\mathrm{PH}$ Forschung und Entwicklung

AG Forschung und Entwicklung Pflanzenschutz

Dr. Athanassios Tzikas

FC Forschung und Entwicklung

Zu einem Technischen Experten

Dr. Roland Bauhofer $\quad$ FC Marketing

Zu einem Experten für Informatik

Ulrich Gentsch, dipl. Math. IS Computer Communication Center

Zu Wissenschaftlichen Spezialisten

Willi Bättig, Chem. HTL

Dr. Nico Cerletti

Peter H. Degen, Chem. CG

Dr. Kurt Dietliker

Dr. John M. Ford

Dr. Dimiter Hadjistamov

Frau Dr. Kathleen Hauser

Dr. Christian Landes

Dr. Helmut Mett

Dr. Jin Mizuguchi

Dr. Dieter Nordmeyer

Dr. Udo Plüc

Frau Dr. Erika Schmidt

Dr. Thomas Schupp

Dr. Rolf Schurter

Rudolf Zink, Chem. CG

AG Produktion

PH Forschung und Entwicklung

$\mathrm{PH}$ Forschung und Entwicklung

$\mathrm{AD}$ Forschung

$\mathrm{PH}$ Forschung und Entwicklung

KU Technik

PH Forschung und Entwicklung

AG Toxikologie-Dienste

$\mathrm{PH}$ Forschung und Entwicklung

FO Materialforschung

AG Forschung und Entwicklung Pflanzenschutz

AG Forschung und Entwicklung Pflanzenschutz

FD Physik

$\mathrm{PH}$ Forschung und Entwicklung

AG Forschung und Entwicklung Pflanzenschutz

Zu Technischen Spezialisten

Rolf Günther, dipl. Ing.

Dr. Peter Oggenfuss

Dr. Gerhard Reinert

Dr. Theodor Steiner

August Tinner, Chem. HTL

FC Forschung und Entwicklung

Zu Spezialisten für Informatik

Gilbert Bastard, dipl. Ing.

Rene Burkhardt, dipl. Phys.

Boudewijn Coster

FC Marketing

AG Produktion

FC Forschung und Entwicklung

AG UB Tiergesundheit

KU Technik

Pierre Hasselmann, dipl. Ing.

Dr. Rainer Nutz

Alex Sele, Chem. CG

Willem Vaessen, M. Sc.

Toni Walch

WM Controle et informatique

IT Beratung

IS Applikationsentwicklung/ Materialwirtschaft

AG Planung, Information, Control und Divisionale Dienstleistungen

PH Regionen Management und PIC

PH Forschung und Entwicklung

PH Technik

IS Grossrechnertechnik

Zu Betriebswirtschaftlichen Spezialisten

Eduard Egger, Ing. grad.

Egon F. Ulshöfer
PH Regionen Management und PIC

PI Planung/Information / Control 
4th International Conference on the Applications of Density Functional Theory in Chemistry and Physics

Centro Stefano Franscini, Monte Verita, Ascona, Switzerland, September 23-29, 1991

Organized by C. Daul (University of Fribourg), M. Posternak (EPF Lausanne) and J. Weber (University of Geneva). The conference will treat all aspects of Density Functional Theory (DFT), with special attention being paid to applications in chemistry and physics, including: (i) electronic structure calculations and structural energy minimizations; (ii) calculation of chemical and physical properties; (iii) molecular dynamics and Car-Parrinello type DFT; (iv) new methodological developments in DFT and beyond. Lectures by J. Andzelm, E.J. Baerends, R. Car, H. Chermette, J.P. Daudey, R.O. Jones, E. Ludena, R.G. Parr, and M. Schluter. For further information, contact: $\mathrm{Dr}$. C. Daul, Institute of Inorganic Chemistry, University of Fribourg, Perolles, 1700Fribourg, Switzerland (Tel:037/82.64.36;EM:CDAUL@ CFRUNI52).

\section{Givaudan \& Cie SA}

Die L. Givaudan \& Cie SA in Genf, eine Tochtergesellschaft der Roche Holding AG in Basel, hat die Übernahme der Fritzsche Dodge \& Olcott(FDO), New York, und deren weltweiten Aktivitäten auf den 31. Dezember 1990, bekanntgegeben. FDO war bis heute im Besitz der BASF K\&F Corporation, einer Tochtergesellschaft der deutschen BASF AG, Ludwigshafen, Deutschland.

Die Acquisition ist in Übereinkunft mit dem schon früher bekanntgegebenen Abkommen. Zum Preis der Transaktion wurden keine Angaben gemacht.

Givaudan ist einer der führenden internationalen Hersteller von Aromen, Parfüms und Aromachemikalien und erzielte 1989 weltweit Verkäufe von 530 Mio US\$. FDO entwickelt, produziert und vertreibt Aromen- und Riechstoffe und wies 1989 einen Umsatz von 120.4 Mio.US\$ auf. Mit dieser Übernahme erschliessen sich Givaudan neue Absatzmöglichkeiten in den Segmenten der Lebensmittelindustrie und zusätzliche Verkäufe in den Bereichen der Parfümkompositio- nen und Aromachemikalien zur Herstellung von Kosmetika, Toilettenartikel und Haushaltprodukten.

Gemäss einem Integrationsplan, der aufgrund eines am 1. Januar 1991 beginnenden Evaluationsverfahrens erstellt wird, soll FDO mit Givaudan fusioniert werden. Die entsprechenden Integrationskomitees, die dieses Evaluationsverfahren durchführen werden, bestehen aus Mitgliedern beider Firmen in den USA sowie weiteren Ländern in denen FDO mit Filialen vertreten ist.

Diese Acquisition entspricht der von Roche verfolgten Strategie, sich auf ihre vier Aktivitätsbereiche zu konzentrieren: pharmazeutische Spezialitäten, Vitamine und Feinchemikalien, Diagnostika, sowie Riechstoffe und Aromen. Roche Holding $A G$ ist die Muttergesellschaft einer weltweit tätigen Gruppe forschender Unternehmen im Gesundheitswesen, deren Aktivitäten das ganze Spektrum von Vorbeugung, Erkenntnis und Behandlung von Krankheiten umfassen.

\section{Grammatikakis-Neumann Prize in Photochemistry}

In 1991, a Prize from the Grammatikakis-Neumann Fund of the European Photochemistry Association, Section Switzerland (Swiss Society of Photochemistry and Photophysics), will be awarded to a young research scientist for outstanding contributions in the field of photochemistry. The award followed by the lecture of the prizewinner is scheduled for October 1991, at the Annual Meeting of EPASwitzerland, Lausanne, Switzerland.
You are invited to submit nominations or applications including curriculum vitae, list of publications, reprints, and preprints to the president of the jury

Prof. Dr. Gion Calzaferri Inst. of Inorganic and Physical Chemistry

University of Bern

CH-3000 Bern 9

by June 1,1991 .

Beförderungen in der Industrie

CHIMIA 45 (1991) Nr.1/2 (Januar/Februar)

\section{Ciba-Geigy AG}

Der Verwaltungsrat und die Konzernleitung haben mit Wirkung ab

1. Januar 1991 folgende Ernennungen im Rahmen der Parallelhierarchie beschlossen:

Zu Wissenschaftlichen Experten

Dr. Hans-Ulrich Blaser

Dr. Satish Chandra Khanna

Dr. Cesare Mondadori

Dr. Burkhard Sechser

FD Katalyse und Synthesedienste

$\mathrm{PH}$ Forschung und Entwicklung

$\mathrm{PH}$ Forschung und Entwicklung

AG Forschung und Entwicklung Pflanzenschutz

Dr. Athanassios Tzikas

FC Forschung und Entwicklung

Zu einem Technischen Experten

Dr. Roland Bauhofer $\quad$ FC Marketing

Zu einem Experten für Informatik

Ulrich Gentsch, dipl. Math. IS Computer Communication Center

Zu Wissenschaftlichen Spezialisten

Willi Bättig, Chem. HTL

Dr. Nico Cerletti

Peter H. Degen, Chem. CG

Dr. Kurt Dietliker

Dr. John M. Ford

Dr. Dimiter Hadjistamov

Frau Dr. Kathleen Hauser

Dr. Christian Landes

Dr. Helmut Mett

Dr. Jin Mizuguchi

Dr. Dieter Nordmeyer

Dr. Udo Plüc

Frau Dr. Erika Schmidt

Dr. Thomas Schupp

Dr. Rolf Schurter

Rudolf Zink, Chem. CG

AG Produktion

PH Forschung und Entwicklung

$\mathrm{PH}$ Forschung und Entwicklung

$\mathrm{AD}$ Forschung

$\mathrm{PH}$ Forschung und Entwicklung

KU Technik

PH Forschung und Entwicklung

AG Toxikologie-Dienste

$\mathrm{PH}$ Forschung und Entwicklung

FO Materialforschung

AG Forschung und Entwicklung Pflanzenschutz

AG Forschung und Entwicklung Pflanzenschutz

FD Physik

$\mathrm{PH}$ Forschung und Entwicklung

AG Forschung und Entwicklung Pflanzenschutz

Zu Technischen Spezialisten

Rolf Günther, dipl. Ing.

Dr. Peter Oggenfuss

Dr. Gerhard Reinert

Dr. Theodor Steiner

August Tinner, Chem. HTL

FC Forschung und Entwicklung

Zu Spezialisten für Informatik

Gilbert Bastard, dipl. Ing.

Rene Burkhardt, dipl. Phys.

Boudewijn Coster

FC Marketing

AG Produktion

FC Forschung und Entwicklung

AG UB Tiergesundheit

KU Technik

Pierre Hasselmann, dipl. Ing.

Dr. Rainer Nutz

Alex Sele, Chem. CG

Willem Vaessen, M. Sc.

Toni Walch

WM Controle et informatique

IT Beratung

IS Applikationsentwicklung/ Materialwirtschaft

AG Planung, Information, Control und Divisionale Dienstleistungen

PH Regionen Management und PIC

PH Forschung und Entwicklung

PH Technik

IS Grossrechnertechnik

Zu Betriebswirtschaftlichen Spezialisten

Eduard Egger, Ing. grad.

Egon F. Ulshöfer
PH Regionen Management und PIC

PI Planung/Information / Control 
4th International Conference on the Applications of Density Functional Theory in Chemistry and Physics

Centro Stefano Franscini, Monte Verita, Ascona, Switzerland, September 23-29, 1991

Organized by C. Daul (University of Fribourg), M. Posternak (EPF Lausanne) and J. Weber (University of Geneva). The conference will treat all aspects of Density Functional Theory (DFT), with special attention being paid to applications in chemistry and physics, including: (i) electronic structure calculations and structural energy minimizations; (ii) calculation of chemical and physical properties; (iii) molecular dynamics and Car-Parrinello type DFT; (iv) new methodological developments in DFT and beyond. Lectures by J. Andzelm, E.J. Baerends, R. Car, H. Chermette, J.P. Daudey, R.O. Jones, E. Ludena, R.G. Parr, and M. Schluter. For further information, contact: $\mathrm{Dr}$. C. Daul, Institute of Inorganic Chemistry, University of Fribourg, Perolles, 1700Fribourg, Switzerland (Tel:037/82.64.36;EM:CDAUL@ CFRUNI52).

\section{Givaudan \& Cie SA}

Die L. Givaudan \& Cie SA in Genf, eine Tochtergesellschaft der Roche Holding AG in Basel, hat die Übernahme der Fritzsche Dodge \& Olcott(FDO), New York, und deren weltweiten Aktivitäten auf den 31. Dezember 1990, bekanntgegeben. FDO war bis heute im Besitz der BASF K\&F Corporation, einer Tochtergesellschaft der deutschen BASF AG, Ludwigshafen, Deutschland.

Die Acquisition ist in Übereinkunft mit dem schon früher bekanntgegebenen Abkommen. Zum Preis der Transaktion wurden keine Angaben gemacht.

Givaudan ist einer der führenden internationalen Hersteller von Aromen, Parfüms und Aromachemikalien und erzielte 1989 weltweit Verkäufe von 530 Mio US\$. FDO entwickelt, produziert und vertreibt Aromen- und Riechstoffe und wies 1989 einen Umsatz von 120.4 Mio.US\$ auf. Mit dieser Übernahme erschliessen sich Givaudan neue Absatzmöglichkeiten in den Segmenten der Lebensmittelindustrie und zusätzliche Verkäufe in den Bereichen der Parfümkompositio- nen und Aromachemikalien zur Herstellung von Kosmetika, Toilettenartikel und Haushaltprodukten.

Gemäss einem Integrationsplan, der aufgrund eines am 1. Januar 1991 beginnenden Evaluationsverfahrens erstellt wird, soll FDO mit Givaudan fusioniert werden. Die entsprechenden Integrationskomitees, die dieses Evaluationsverfahren durchführen werden, bestehen aus Mitgliedern beider Firmen in den USA sowie weiteren Ländern in denen FDO mit Filialen vertreten ist.

Diese Acquisition entspricht der von Roche verfolgten Strategie, sich auf ihre vier Aktivitätsbereiche zu konzentrieren: pharmazeutische Spezialitäten, Vitamine und Feinchemikalien, Diagnostika, sowie Riechstoffe und Aromen. Roche Holding $A G$ ist die Muttergesellschaft einer weltweit tätigen Gruppe forschender Unternehmen im Gesundheitswesen, deren Aktivitäten das ganze Spektrum von Vorbeugung, Erkenntnis und Behandlung von Krankheiten umfassen.

\section{Grammatikakis-Neumann Prize in Photochemistry}

In 1991, a Prize from the Grammatikakis-Neumann Fund of the European Photochemistry Association, Section Switzerland (Swiss Society of Photochemistry and Photophysics), will be awarded to a young research scientist for outstanding contributions in the field of photochemistry. The award followed by the lecture of the prizewinner is scheduled for October 1991, at the Annual Meeting of EPASwitzerland, Lausanne, Switzerland.
You are invited to submit nominations or applications including curriculum vitae, list of publications, reprints, and preprints to the president of the jury

Prof. Dr. Gion Calzaferri Inst. of Inorganic and Physical Chemistry

University of Bern

CH-3000 Bern 9

by June 1,1991 .

Beförderungen in der Industrie

CHIMIA 45 (1991) Nr.1/2 (Januar/Februar)

\section{Ciba-Geigy AG}

Der Verwaltungsrat und die Konzernleitung haben mit Wirkung ab

1. Januar 1991 folgende Ernennungen im Rahmen der Parallelhierarchie beschlossen:

Zu Wissenschaftlichen Experten

Dr. Hans-Ulrich Blaser

Dr. Satish Chandra Khanna

Dr. Cesare Mondadori

Dr. Burkhard Sechser

FD Katalyse und Synthesedienste

$\mathrm{PH}$ Forschung und Entwicklung

$\mathrm{PH}$ Forschung und Entwicklung

AG Forschung und Entwicklung Pflanzenschutz

Dr. Athanassios Tzikas

FC Forschung und Entwicklung

Zu einem Technischen Experten

Dr. Roland Bauhofer $\quad$ FC Marketing

Zu einem Experten für Informatik

Ulrich Gentsch, dipl. Math. IS Computer Communication Center

Zu Wissenschaftlichen Spezialisten

Willi Bättig, Chem. HTL

Dr. Nico Cerletti

Peter H. Degen, Chem. CG

Dr. Kurt Dietliker

Dr. John M. Ford

Dr. Dimiter Hadjistamov

Frau Dr. Kathleen Hauser

Dr. Christian Landes

Dr. Helmut Mett

Dr. Jin Mizuguchi

Dr. Dieter Nordmeyer

Dr. Udo Plüc

Frau Dr. Erika Schmidt

Dr. Thomas Schupp

Dr. Rolf Schurter

Rudolf Zink, Chem. CG

AG Produktion

PH Forschung und Entwicklung

$\mathrm{PH}$ Forschung und Entwicklung

$\mathrm{AD}$ Forschung

$\mathrm{PH}$ Forschung und Entwicklung

KU Technik

PH Forschung und Entwicklung

AG Toxikologie-Dienste

$\mathrm{PH}$ Forschung und Entwicklung

FO Materialforschung

AG Forschung und Entwicklung Pflanzenschutz

AG Forschung und Entwicklung Pflanzenschutz

FD Physik

$\mathrm{PH}$ Forschung und Entwicklung

AG Forschung und Entwicklung Pflanzenschutz

Zu Technischen Spezialisten

Rolf Günther, dipl. Ing.

Dr. Peter Oggenfuss

Dr. Gerhard Reinert

Dr. Theodor Steiner

August Tinner, Chem. HTL

FC Forschung und Entwicklung

Zu Spezialisten für Informatik

Gilbert Bastard, dipl. Ing.

Rene Burkhardt, dipl. Phys.

Boudewijn Coster

FC Marketing

AG Produktion

FC Forschung und Entwicklung

AG UB Tiergesundheit

KU Technik

Pierre Hasselmann, dipl. Ing.

Dr. Rainer Nutz

Alex Sele, Chem. CG

Willem Vaessen, M. Sc.

Toni Walch

WM Controle et informatique

IT Beratung

IS Applikationsentwicklung/ Materialwirtschaft

AG Planung, Information, Control und Divisionale Dienstleistungen

PH Regionen Management und PIC

PH Forschung und Entwicklung

PH Technik

IS Grossrechnertechnik

Zu Betriebswirtschaftlichen Spezialisten

Eduard Egger, Ing. grad.

Egon F. Ulshöfer
PH Regionen Management und PIC

PI Planung/Information / Control 
Zu Spezialitäten für Patente

Dr. Volker Buss $\quad$ FD Patente

Dr. Dirk Hillebrand FD Patente

Zu Spezialisten für Ausbildung

$\begin{array}{lll}\text { Rene Auer } & \text { PE } & \begin{array}{l}\text { Personalentwicklung und } \\ \text {-ausbildung }\end{array} \\ \text { Dr. Rudolf Strauch } & \text { HR } & \text { Management-Ausbildung Konzern }\end{array}$

Zu einem Spezialisten für Marketing-Ausbildung

Dr. Dieter Steinbrecher $\quad$ PH Marketing

Zu einem Spezialisten für Lizenzwesen

Dr. Ivan Csendes $\quad$ PH Neue Geschäftsbereiche
Zu einem Spezialisten für Registrierung

Michael Neale, M.Sc. $\quad$ AG Forschung und Entwicklung Pflanzenschutz

Zu einem Spezialisten für Wissenschaftliche Information

Dr. Jean-François Moser

AG Produktion

\section{Lonza AG}

Per 1. Januar 1991 wurden folgende Herren befördert:

Direktor

Stv. Direktor

Vizedirektor

Karl-Heinz. Becker

Dr. Beat In-Albon

Zeichnungsberechtigter Dr. Adriano Faucci

Prokuristen Dr. Felix Pervidoli

Ing. Anton Zenklusen
Gratis-Unterlagen

Bestellungen

\section{CHIMIA}

Probenummer, kostenlos, mit CHIMIA-Prospekt

Jahresabonnement für 1991

Schweiz: Fr. 156.- inkl. Porto

Ausland: Fr. 170.- inkl. Porto $\square$ Luftpostzuschlag: Fr. 69.-

Einzelnummer

Schweiz: Fr. 20.- inkl. Porto $\square$ Ausland: Fr. 25.- inkl. Porto

Einbanddecken

$\square$ in Plastic, mit Halterung: $\square$ in Leinen (1990), ohne Halterung:

Fr. 21.- inkl. Porto $\mathrm{CH}$

Fr. 32.- inkl. Porto $\mathrm{CH}$

Jahreseinbände

in Leinen, Inhalt angeliefert: Fr. 93.- inkl. Porto CH

Frühere Jahrgänge

ungebunden

gebunden

1988: Fr. 183.- inkl. Porto CH

1989: Fr. 183.- inkl. Porto CH

1990: Fr. 183.- Porto $\mathrm{CH}$

Fr. 276.- inkl. Porto $\mathrm{CH}$

Fr. 276.- inkl. Porto $\mathrm{CH}$

Fr. 276.- inkl. Porto $\mathrm{CH}$

Name

Firma

Strasse

PLZ Ort 